If has been reproduced from the hest available copy to permit the b:orest

\title{
High-Field Dipoles for Future Accelerators
}

\author{
Stefan L. Wipf
}

\section{DISCLAIMER}

\begin{abstract}
This report
Government. was prepared as an account of work

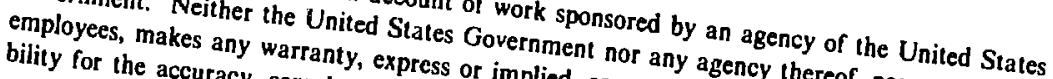
bility for the accuracy, completeness, or implied, or assumes any thereof, nor any of their ence herein to ar represents that its use whess of any information, liability or responsimanufacturer, or specific commercial product not infringe privately apparatus, product, or mendation, or favoringise does not necessarily process, or service by trade naghts. Referand opinions of authors the United States Governme or imply its endorsement, trademark, United States Governmors expressed herein Government or any agency thersement, recomUtates Government or any agency thereof.
necessarily state or reflect the The views
\end{abstract}




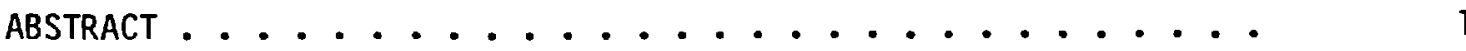

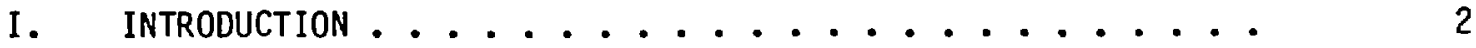

II. OVERVIEW ..................... 4

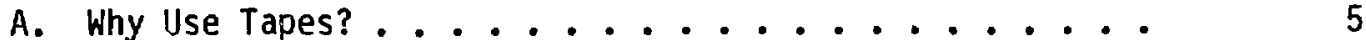

B. How to Overcome Problems Posed

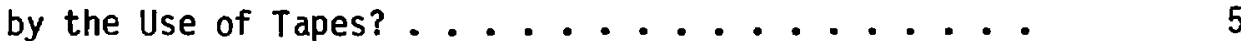

C. What Work Is Necessary and Why Do it Now? ...... 6

III. PROBLEM OF COST-OPTIMIZATION . . . . . . ..... 7

IV. PROSPECTS FOR HIGH-FIELD MAGNETS ........... 9

A. Present Possibilities ................. 9

B. Cost of Superconductors in Dipoles .......... 12

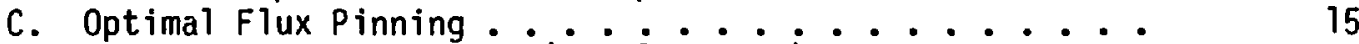

D. Comparison of Different (Single-Layer) 10

E. Dipoles with Severai Layers $\ldots \ldots$

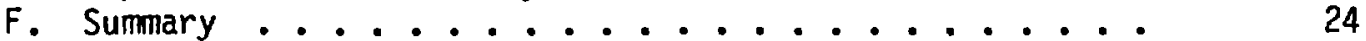

v. PAST EFFORTS (Historicai Summary) ......... $2^{r}$

VI. PROBLEMS TO BE ADDRESSED AND POSSIBLE SOLUTIONS ...... 26

A. Stability and Degradation ............ 28

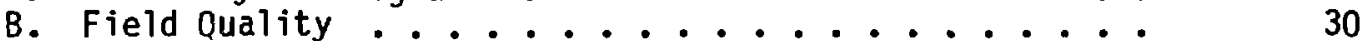

C. Force Containment ................. 31

VII. PROPOSED WORK AND GOALS ............... 32

A. Work to Be Done .................... 33

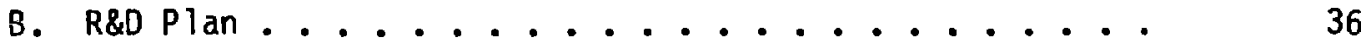

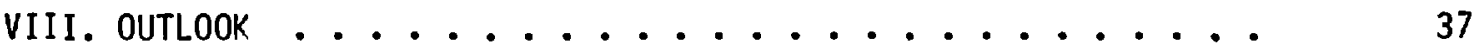

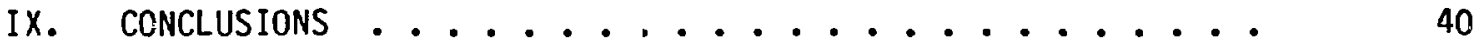

ACKNOWLEDGMENT ........................... 41

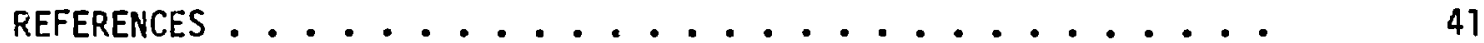


HIGH-FIELD DIPOLES FOR FUTURE ACCELERATORS

by

S. L. Wipt

ABSTRACT

This report presents the concept for building superconducting accelerator dipoles with record high fields. Economic consicierations favor the highest possible current density in the windings. Further discussion indicates that there is an optimal range of pinning strength for a superconducting material and that it is not likely for multifilamentary conductors to ever equal the potential performance of tape conductors. A dipole design with a tape-wound, inner high-field winding is suggested. Methods are detailed to avoid degradation caused by flux jumps and to overcome problems with the dipole ends. Concerns for force support structure and field precision are also addressed. An R\&D program leading to a prototype 11-T dipole is outlined. Past and future importance of superconductivity to highenergy physics is evident from a short historical survey. Successful dipoles in the 10- to 20-T range will allow interesting options for upgrading present 1 argest accelerators. 


\section{INTRODUETION}

High-energy $(B=V / C \simeq 1)$ particle accelerators consist of a channel in which a particle beam is contained and accelerated. Containment and acceleration is by magnetic and electric fields, respectively. For a circular accelerator, the available magnetic dipole bending field $B$ is important; for a linear accelerator, it is the available electric accelerating field $\varepsilon$. We can get a rough equivalence between bending field and accelerating field by comparing the circumference of a circular accelerator, $L>2 \pi \rho=2 \pi E /(e c B)$ with the length of a linear accelerator, $L>E /(e \varepsilon)$, both for a particle energy $E$. Similar $L$ is obtained for $\varepsilon=B c / 2 \pi$. Accordingly, a bending field of $1 T$ corresponds to an accelerating field of $50 \mathrm{MeV} / \mathrm{m}$.

Present state of the art allows accelerating fields of approximately $5 \mathrm{MV} / \mathrm{m}$. With superconducting cavities, still under development, some $10 \mathrm{MV} / \mathrm{m}$ may be obtainable. There are new and mostly (as yet) untested concepts being discussed that (in the distant future) may reach accelerating fields in excess of $100 \mathrm{MV} / \mathrm{m}^{1}$

On the other hand, technology for dipole fields of $5 \mathrm{~T}$ is well established. In view of the discussion just given, we can say that available bending fields are one to two orders oi magnitude stronger than available accelerating fields; therefore, new high-energy accelerators will be circular for some time to come. This state of affairs is reflected by the energies obtained in the largest existing circular and linear accelerators: 1000-GeV at Fermi National Accelerator Laboratory (FNAL) versus 24-GeV at Stanford Linear Accelerator Center (SLAC).

It can be assumed that in the quest for high-energy accelerators, the availability of the highest possible dipole fields will remain important.

In the present report ${ }^{\dagger}$ the question of how to reach dipole fields beyond $10 \mathrm{~T}$ is discussed. Three general aspects are dealt with: (1) economic considerations, (2), outlook for the future, (3) scientific problems and suggested solutions. To the reader who might think that the order of the three aspects should be different, I must point out that research with specific applications as a goal, of which this is an example, can only be justified if

TThis report is based on an R\&D proposal submitted to DOE in March 1984. 
the promise of economic advantage can be established and if, after the several years necessary for the development of the concepts, there is still a likely market for its applications. Without positive answers to these two aspects, unfortunately, the most elegant scientific solution counts for little.

At this stage the basic ideas and the technical solutions to the stated problems are conceptual; that is, their viability has to be established by research. Nothing is proposed that does not look reasonable, no insuperable problems are anticipated, no breakthroughs will be needed. Nevertheless, research is the way to "look into the seeds of time and say which grain will grow and which will not." ${ }^{\dagger}$

The report is organized as follows: Economic considerations are discussed in Secs. III and IV. The outlook for the future is discussed in Secs. V and VIII. The technical solution is described in Secs. II, VI, and VII.

Section II gives an overview emphasizing the proposed technical innovations. Section III addresses the problem of cost optimization as a function of bending magnet strength for a high-enerqy accelerator, using as an example the Superconducting Super Collider (SSC). At present there is no clear evidence in favor of a particular level of field strength, but higher fields than the available $5 \mathrm{~T}$ are desirable.

Section IV discusses the outlook for high-field magnets $(>8 \mathrm{~T}$ ) and the special problems blocking immediate progress: the influence of the critical current density and the relative cost of superconductors are crucial. For fields of $10 \mathrm{~T}$ and higher, the multifilamentary high-field conductors have insufficient critical current density. Tapes can give current densities more than twice as high; at the same time, their cost may be only half.

In Sec. VI a short account is given of past efforts as an orientation for needed progress. Future dipole requirements will be in the 10- to 20-T range. In the past, high-energy physics has promoted one of the most significant developments in superconductor technology, namely, the multifilament conductor. Because of the success of multifilament conductor, tape conductor became redundant for most practical purposes. However, R\&D for superconducting transmission lines generated highly developed tape conductors.

FWilliam Shakespeare, "Macbeth." 
In Sec. VI the problems to be solved are listed and methods for solving them are suggested. Problems that are specific to using tape conductors are flux jumps (which should be avoided), the current distribution within the tape, and the construction of dipole ends. It will be necessary to place the tape with its face parallel to the field. In the two-dimensional section of the dipole, this condition can be satisfied. In the end regions, in addition to choosing a suitable winding geometry, careful shaping of the fields by means of interleafed superconducting tapes and also by means of the iron yokes will be required. It will be easier to build dc dipoles, that is, dipoles that only have to perform at their maximum field level; developing ac dipoles will be a more difficult task.

The necessary work to be done is discussed in Sec. VII. A conceptual high-field dipole is proposed. It has an outer winding based on existing technology of multifilamentary NbTi, good for about $5 \mathrm{~T}$, and an inner winding of $\mathrm{Nb}_{3} \mathrm{Sn}$ tape for the additional $6 \mathrm{~T}$. The concept is to be researched by making detailed field and force calculations and by testing small models of endwinding geometries employing superconducting tape. The results will serve for subsequent design, manufacturing, and testing of a 2-m-long dipole. A tentative R\&D timetable is also set out. The chief goal, a model prototype dc 11-T dipole, could be reached in 3 years. The first year would be used in testing the suggested concepts before freezing a design.

Section VIII gives an outlook on the possibilities that become available if sucessful tape dipoles can be built. High-field dc dipoles can be used in storage rings, or in accelerators if combined with ac dipoles of lower field. A coripact SSC for collision of $14.5 \mathrm{TeV}$ on $20-\mathrm{TeV}$ beams could be accommodated in an 18-km-diam ring. Further development can lead toward full ac capabi1ities and/or yet higher fields, up to $18 \mathrm{~T}$. Future expansion of a 20-TeV SSC up to $100 \mathrm{TeV}$ becomes possible. In Sec. VIII a brief summation of the concept is given, which concludes the report.

\section{OVERVIEW}

High-field accelerator dipole magnets using superconducting tape have the potential advantages of lower cost and higher fields than those expected with the alternative of using multifilamentary conductors. 


\section{A. Why Use Tapes?}

To reach dipole fields of $10 \mathrm{~T}$, and beyond, with superconductors is an unsolved problem. The dipoles must be suitable for accelerators; that is, they must satisfy stringent requirements for field quality, but they also must be economical both in material and manufacturing cost. Because the needed apertures are relatively small, economy dictates the highest possible current density in the windings. Tape can give the highest current density.

The two traditional approaches towards creating high dipole fields-so far unsuccessful in reaching $10 \mathrm{~T}$-are incapable of sufficiently high current densities. In one approach, $\mathrm{NbTi}$ is to be used at $1.9 \mathrm{~K}$, but the upper critical field of this material is low enough to cause sharply reduced critical currents for fields $>9 \mathrm{~T}$. In the other approach, $\mathrm{Nb}_{3} \mathrm{Sn}$ multifilament is the chosen conductor; unfortunately, the process of manufacturing multifilament requires bronze and diffusion barriers in the finished product, and both components, being nonsuperconducting, reduce the highest critical current densities attainable. The $\mathrm{Nb}_{3} \mathrm{Sn}$, processed as a tape, does not have this limitation.

The two traditional approaches suffer from nasty engineering problems. The $\mathrm{Nb}_{3} \mathrm{Sn}$ multifilament conductor is quite brittle and demands either large bending radii or else the final wire-manufacturing step: a reaction of several hours at $>600^{\circ} \mathrm{C}$, after winding of the coil (wind-and-react method). The use of $\mathrm{NbTi}$ at $1.9 \mathrm{~K}$ requires a less simple, more expensive cryogenic system and leads to very small stability margins-in fact, too small to reach reliably $B \geq 10 \mathrm{~T}$. The tape approach, too, has some peculiar engineering problems, but we have conceptual solutions to them.

\section{B. How to Overcome Problems Posed by the Use of Tapes?}

Experience with large tape-wound coils (before the availability of multifilamenc conductors) taught us the importance of having the tape face and magnetic field parallel, sufficiently so that the perpendicular component does not exceed a few kilogauss. Such an alignment is necessary to avoid flux jumps, which cannot be toleraced; at $10 \mathrm{~T}$, the alignment needs to be better than $\pm 1^{\circ} 30^{\prime}$ to achieve this parallel arrangement. An even better alignment is desirable because it can reduce induced currents that cause multipole errors and ac losses. Indeed, given a sufficiently good alignment, tape can behave quite like multifilament wire with filament diameter comparable to the thickness of the active layer in the tape. 
An accelerator dipole has two distinct regimes concerning field and winding geometry: In the useful part of the dipole, the field is two-dimensional; it is relatively straightforward, especially in the high-field layers, to place the tape windings parallel to the field. The two ends pose more of a challenge. In the end regions, the fields are three-dimensional, making detailed computations more difficult. However, these three-dimensional end regions are comparatively small when considering the 5- to 10-m length of the dipole. Consequently, the field quality of the end sections in the beam tube is less important; also, highest current density is not necessary. In the end regions, therefore, one can focus on the conditions that are of great importance when using tape: The winding geometry is constrained by the necessity of the conductors having to cross over the beam pipe; furthermore, the fields must still be parallel to the tape locally, and they must not be so high that they cause quenches by exceeding the critical values for the conductors. In fact, the fields in the end regions must be considerably lower to allow placement of the bends of the outer layer low-field windings. A geometry that can fulfill these conditions is illustrated and discussed in Sec. VII.

To achieve parallelity in the end regions, the local field direction can be influenced by two methods: (a) additiona? pieces of superconducting tapes interleaved with the tape windings and (b) iron piaced above and below the tape stacks. Both superconductors and iron influence the field shape by induced currents that tend to form mirror images of the original field-producing currents. The induced currents cause the rield lines to be parallel to the superconducting surfaces and perpendicular to the iron surfaces.

\section{What Work Is Necessary, and Why Do it Now?}

It is clear that some research is needed to establish whether or not the proposed concepts are sound and workable. And, a hallmark of real research, a positive answer cannot be guaranteed.

Detailed field and force calculations, in combination with small-scale experimental tests on end geometries with superconducting tapes, will be made first. The resuits of such tests will constitute progress in superconducting technology. If the results are positive, the design, manufacturing, and testing of a 2-m-long-model prototype dipole for $11 \mathrm{~T}$ will follow. 
A successfu\} outcome will open very promising prospects:

- Further development of high-field dipoles up to $18 \mathrm{~T}$

- A compact high-energy ring design

- Future upgrade of existing high-energy accelerators, for instance up to quintupling the beam energy of a $20-\mathrm{TeV}$ SSC

\section{PROBLEM OF COST-OPTIMIZATION}

From a plot of cost versus energy of existing accelerators (Fig. 1) we read that reasonable expectations for a 20-TeV machine are in the range of 1-2 M\$/GeV. The total (capital) cost would thus be between 2 and $4 \mathrm{G} \$$. Quite likely the data in Fig. 1 do not include such costs as R\&D, which could be high because almost each machine was a prototype, or costs for the laboratory facilities, including real estate, necessary to accommodate the accelerator.

of great importance, but difficult to gauge, are the operational costs over the lifetime of the accelerator. Power costs, for instance, have necessitated prolonged shutdowns in large accelerators, hence the trend to use superconducting magnets. Some kind of economic balance between capital and operational costs should not be overlooked either. At $10 \%$, the cost of $3 \mathrm{G \$}$ over 30 years is $318 \mathrm{~m} \$ / \mathrm{yr}$ or $36 \mathrm{k} \$ / \mathrm{h}$. This then is, roughly, the cost of idling the machine because of equipment failure. More expensive components of higher quality can thus be justified.

A simple example may illustrate this point. Consider the quality of dipoles. Assume "high quality" to imply that one-third of the units have to be replaced (or repaired) during the lifetime of 30 years; twice as many if "medium quality"; and three times as many, or all, if "low quality." If the units are $10 \mathrm{~m}$ long, we have to expect (on average) one, two, or three breakdowns/kilometer per year for high-, medium-, or low-quality magnets, respectively. We may further assume that the replacement of a unit involves transport through the tunnel at $10 \mathrm{~km} / \mathrm{h}$ (average distance $\pi R / 2$ ) and $10-\mathrm{h}$ installation time. Using high-quality magnets in a ring of $2 \pi R=200 \mathrm{~km}$ length (bending dipoles $B=2.2 \mathrm{~T}$ ) will still cause an average of 200 failures/yr and a downtime of $3000 \mathrm{~h}$ or $34 \%$ of the total available time. In a ring $50 \mathrm{~km}$ long $(B=10 \mathrm{~T})$, the downtime is only $565 \mathrm{~h}$ or $6.5 \%$ of the time. With mediumquality magnets, the downtimes are twice as long; with low-quality magnets, the large low-field ring is out practically always, whereas, the high-field 


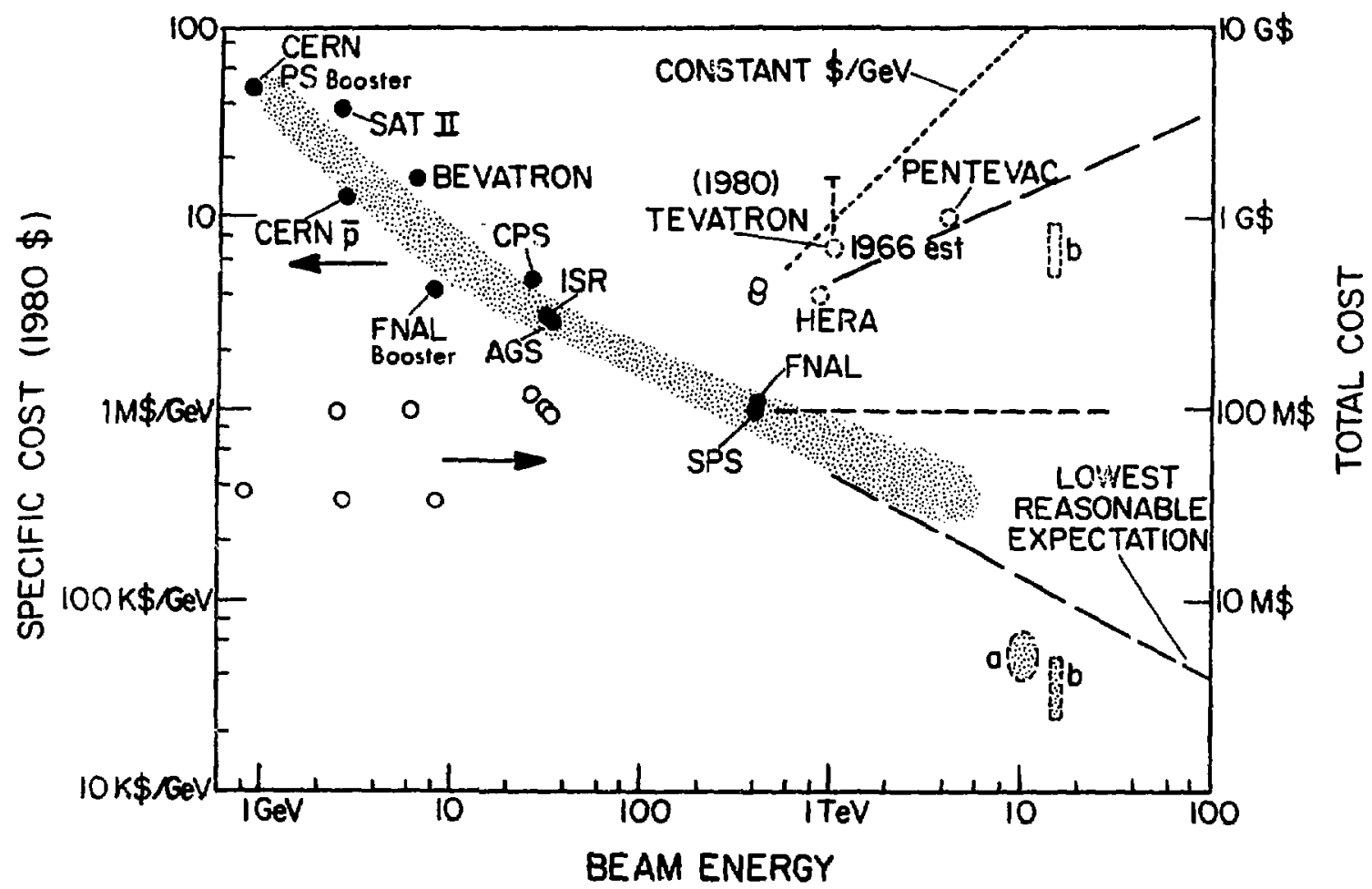

Fig. 1. SPECIFIC ACCELERATOR COST DECREASES WITH INCREASING SIZE AND LEARNING.

Costs of large accelerators versus beam energy.

Costs reported for accelerators built, from Ref. 2, adjusted to 1980\$:

- : specific cost, left scale (shaded area: guide for the eye)

0 : total cost, riaht scale

Estimates of some projected accelerators:

得: specific cost ， a: Desertron, Ref. 3; b: SSC Ref. 4; Pentevac, Ref. 5t;

: total cost Tevatron tt; HERA, Ref. 6.

+ Wilson, in Ref. 5, estimates the 1980 s cost of Pentevac at $500 \mathrm{M} \$$ and quotes the 1970 cost for FNAL main ring as 125 M\$ corresponding so 225 M\$ (1980), which is only half the cost figure (TOTAL COST OF FACILITY) given in Ref. 2. We therefore assumed that the estimate for the complete Pentevac should be twice as large, namely $1000 \mathrm{MS}$.

t+ M. G. White in the article "Synchrotrons" from the Encyclopedia of Prysics, R. M. Besançon, Ed., Reinhold, New York, 1966 (703-706) quotes "serious proposals before the government agencies" for a l-TeV machine at a cost of $700 \mathrm{Ms}$. A factor 2.3 for inflation would bring this figure to $1.6 \mathrm{G}$ (1980\$). The actual cost of the saver/doubler upgrade is given in Ref. 3 as $100 \mathrm{MP}$ [Without cost of errors (!) and R\&D] which, added to the FNAL cost of Ref. 2, would bring the total cost to just below the igbb estimate, 
ring is only down for $20 \%$ of the time. This example shows, independently of the detailed assumptions, the importance of magnet quality and reliability with increasing ring size.

Another general feature seems to emerge when surveying the major capitalcost items of an accelerator such as magnets, refrigeration, tunnel, real estate, injector, beam control and accelerating structure, and experimental areas. Together, magnets, refrigeration, and tunnel account for approximately three-fourths of the total capital cost. The bending-magnet strength $B$ is a major design variable for the accelerator. The length of the ring circumference and (therefore) the tunnel cost is proportional to $1, B$; the cost of magnets per unit length is, very roughily, proportional to $B^{2}$. Realistic unit costs for both tunnel and magnets are such that in the range $2 \mathrm{~T}<\mathrm{B}<10 \mathrm{~T}$, the sum (adding up to about three-fourths of the accelerator cost) is not greatly affected. ${ }^{4}$

Individual cost estimates can vary widely as the examples in Figs. 2 and 3 indicate. Three projections, each for tunnel cost and for magnet cost, can be combined in pairs to indicate cost optima between $2.2<\mathrm{B}<9.4 \mathrm{~T}$ and $0.42<$ cost $<2.25 \mathrm{G} \$$ for tunnel and magnets for a $20-\mathrm{TeV}$ machine. Proper cost optimization will need a specific design.

In general, we can state that the bending field level has no obviously strong influence on overall accelerator cost. Indications are that optimal field levels may be found in a range around $6 \mathrm{~T}$.

This discussion is also applicable for the case of an existing ring tunnel to be upgraded to higher energies. The obtainable energy will simply be proportional to the bending field strength. However, there will be a cost crossover point where the high-field bending magnet cost will be equal to the cost of a new tunnel plus magnets at lower fields. As an example, if magnet cost Curve $b$ in Fig. 2 and tunnel cost Curve $C$ in Fig. 3 are applicable, the crossover will be at $B=11 \mathrm{~T}$ where the magnet cost (see Fig. 2) will be $3 \mathrm{k} \$ / \mathrm{T} \cdot \mathrm{m}$, same as the cost minimum for tunnel + magnet at $B=6 \mathrm{~T}$.

\section{PROSPECTS FOR HIGH-FIELD MAGNETS}

\section{A. Present Possibilities}

There are at present two established, technically developed, superconductors on the market that are considered suitable for accelerator dipoles and 
Fig. 2. COST PROJECTION FOR SUPERCONDUCTING MAGNETS ENCOMPASSES LARGE BRACKETS.

Estimated specific cost of superconducting dipole bending magnets versus dipole field strength.

$$
\begin{aligned}
& \text { a : Ref. } 7^{+}\left(r_{i}=5 \mathrm{~cm} ; \text { unit length } 6 \mathrm{~m}\right) \\
& \text { b : my own guess } \\
& \text { c : Ref. } 8^{\dagger}\left(r_{i}=6 \mathrm{~cm} ; \text { length } 4 \mathrm{~m}\right)
\end{aligned}
$$

FNAL: R. Lundy pers. comm. Jan. 1982 (38 $\mathrm{k} \$$ per unit of $27 \mathrm{~T} \cdot \mathrm{m}, r_{i}=3.8 \mathrm{~cm}$ )

O : Ref.4

+ Hassenzahl's magnet-cost projections from $1981^{8}$ and 1982 ' differ by a factor $>4$. Perhaps it is fair to consider his high estimate as too ressimistic and his low one as too optimistic.

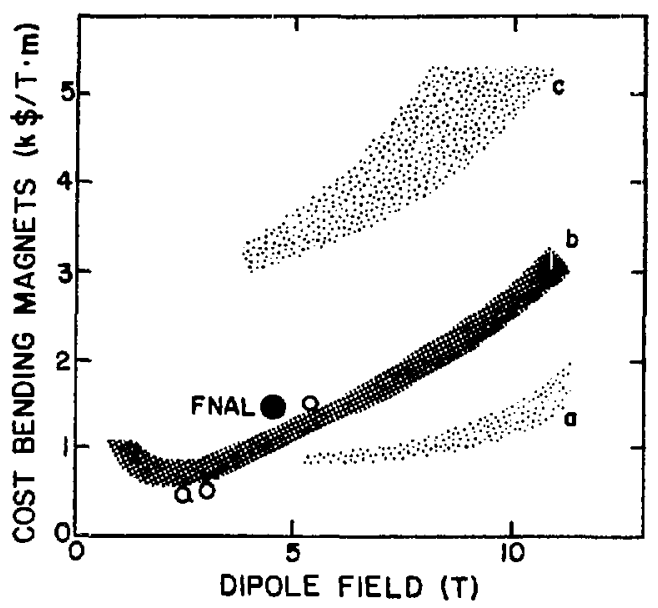

Fig. 3. COST PROJECTION FOR THE MAJOR COMPONENTS OF THE SSC VARIES WILDLY.

Specific cost for tunriel and for bending magnets versus dipole field strength.

Solid curves: Tunnel cost: A: $1 \mathrm{M \$} / \mathrm{km}$, Ref.4

$B: 4 \mathrm{M \$} / \mathrm{km}$, Ref. $9^{++}$

C: $8 \mathrm{M \$} / \mathrm{km}$, Ref. $9^{\mathrm{tt}}$

Magnet cost: a, b, c, after Fig. 2

Dashed_curves: Cost of maginets and tunnel for 20-TeV single ring.

$$
+ \text { : Cost minimum }
$$

t+ $4 \mathrm{M} \$ / \mathrm{km}$ and $8 \mathrm{~m} \$ / \mathrm{km}$ are low and high estimates for underground excavation.

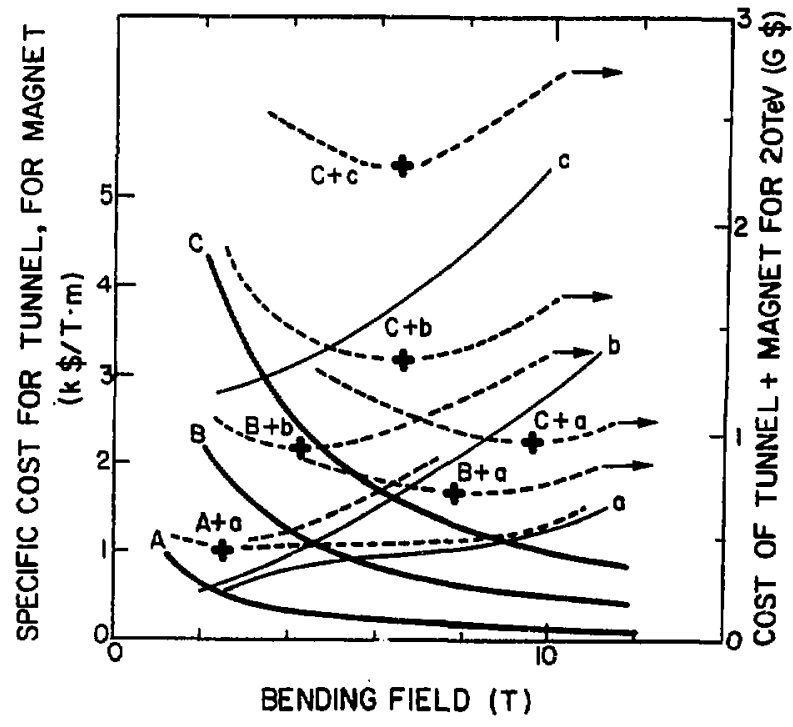

BENDING FIELD (T) 
quadrupoles: $\mathrm{NbTi}$ and $\mathrm{Nb}_{3} \mathrm{Sn}$, both in multifilamentary form. By far the most widely used and best-tested conductor is NbTi. The present state of the art of superconducting accelerator dipoles offers approximately $5 \mathrm{~T}$ in 5 - to 10-cm-diam bore, using NbTi at $4.2 \mathrm{~K}$. This technology is, or will be, used by FNAL Tevatron, HERA, TRISTAN, UNK. ${ }^{10,11}$ It may be that $6 \mathrm{~T}$ can be reached by lowering the operating temperature scmewhat (to $3-3.5 \mathrm{~K}$ ).

Two methods are favored for reaching high fields $(8-1 \cap \mathrm{T})$ :

(a) using NbTi with superfluid helium cooling at $1.9 \mathrm{~K}$ operating temperature; ${ }^{12-14}$

(b) using $\mathrm{Nb}_{3} \mathrm{Sn}$ multifilament conductor at $4.2 \mathrm{~K} .{ }^{15,16}$

Both methods have drawbacks and limitations. Method (a) needs slightly more expensive refrigeration; $10 \mathrm{~T}$ should be considered as the absolute limit for this method; no progress beyond $10 \mathrm{~T}$ can be expected because of the small stability margin caused by the proximity of the upper critical field. Method (b) has problems associated with the peculiarities of $\mathrm{Nb}_{3} \mathrm{Sn}$ : The processed multifilamentary conductor is extremely brittle and does not allow bending around a radius $(r<20 \mathrm{~cm})$ small enough to be useful at the ends of dipoles and quadrupoles. ${ }^{15}$ The standard answer to this problem is the wind-and-react technique where the final processing of the superconductor, involving a heat treatment at $2700^{\circ} \mathrm{C}$ for several hours, is effected after the coil is wound. ${ }^{16}$ The wind-and-react technique puts extraordinary constraints on the choice of materials and designs in the engineering of the coil. The practical field limit for $\mathrm{Nb}_{3} \mathrm{Sn}$ multifilament may be about $11 \mathrm{~T}$ and is set by the limitations in critical current density $j_{c}$. Two effects depress $j_{c}$. One is due to the method of forming the multifilament, which leaves some bronze behind (nonsuperconducting and not useful as stabilizer like pure copper) that is inert and only dilutes the otherwise very high current density in the reacted $\mathrm{Nb}_{3} \mathrm{Sn} .{ }^{17}$ The other effect is an innate disadvantage of $\mathrm{Nb}_{3} \mathrm{Sn}$ : Its flux pinning force $F_{p}=j_{c} \cdot B$ has a maximum at $B \simeq 5 T$ and becomes smaller with in creasing field, being almost an order of magnitude smaller at $15 \mathrm{~T}^{18}$ For most superconductors, $F_{p}$ is approximately constant over a large field range; for example, $V_{3} G a$ has $F_{p}$ roughly constant up to $B \approx 19 T^{19}$ As will be shown below, current density is a limiting factor in the design of efficient dipoles. 


\section{B. Cost of Superconductors in Dipoles}

The cost of superconductors is a substantial portion of the cost of the accelerator magnets and, therefore, of the cost of the whole accelerator.' Although present cost estimates of complete magnets cannot be considered very reliable (see Fig. 2), one can nevertheless gain an understanding of relative merits of different superconductors by discussing relative cost advantages.

In a first approximation to estimating the superconductor cost, a dipole cross section as in Fig. 4 is considered. A winding space of thickness d, between radius $r_{j}$ and $r_{0}$, with a current density $j=j_{0} \cos \phi$ produces a field 20,21

$B_{0}=\frac{\mu_{0}}{2} j_{0} d$.

The current density is related to the critical current density in the superconductor at the field $B_{0}$ :

$j_{0}=\lambda \cdot j_{c}\left(B_{0}\right)$.

The factor $\lambda$ accounts for the space in the winding that is not filled with superconductor, such as insulation, necessary force structure, and (mainly) the copper (or aluminum) used for stabilizing purposes. The range

$0.2<\lambda<0.4$ is available in modern designs.

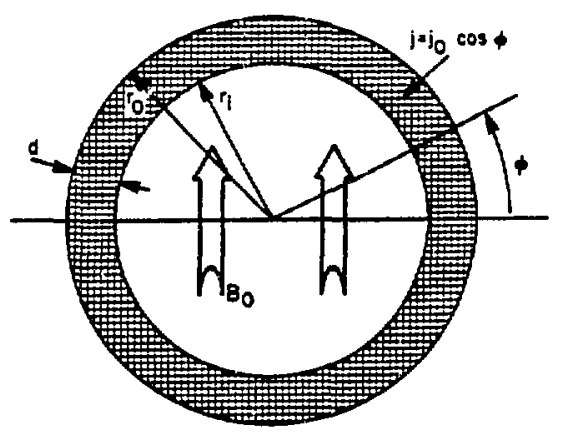

The thickness $d=r_{0}-r_{j}$ of the winding necessary to produce $B$ with a given superconductor is

$d=2 \frac{B_{0}}{\mu_{0} j_{0}}=2 \frac{B_{0}^{2}}{\mu_{0} \lambda F_{p}}$,

where $F_{p}=j_{c} \times B$ is the flux pinning strength, a basic critical propert. $f$ the superconductor.

The volume of the winding is

Fig. 4.

DIPOLE WINDING GEOMETRY FOR SINGLE-LAYER APPROXIMATION.

$V_{w}=2 \pi\left(r_{i}+\frac{d}{2}\right) d$, 
but the volume of the superconducting material itself is smaller by $\lambda$ and a facter $2 / \pi$ because of the $\cos \phi$ distribution; thus,

$V_{s c}=4\left(r_{i}+\frac{\dot{i}}{2}\right) d \lambda=8 \frac{B_{0}^{2}}{\mu_{o} F_{p}}\left(r_{i}+\frac{B_{0}^{2}}{\mu_{0} \lambda F_{p}}\right)$.

The superconductor volume consists therefore of two terms: the first that is due to the aperture $r_{i}$ and the second that is due to the current density (or flux pinning streñgth) determining the thickness of the winding.

To illustrate this equation and relate it to present superconductor performance, we plot in Fig. 5 as $F_{p}$ versus $B_{0}$ the locus of coils containing $V_{s c}=10^{-3} \mathrm{~m}^{3} / \mathrm{m}$ and also those $w^{\prime} i{ }^{p} 10$ and 100 times larger $V_{s c}$. The solid line is for $\lambda=0.2$, the dashed line for $\lambda=0.4$-both for $r_{i}=0$. The three thin dashed lines are for $\lambda=0.2$ and $r_{i}=1,2.5$, and $5 \mathrm{~cm}$. The winding thickness $d$ çarresponding to the given $V_{S c}$ is entered for each curve. In addition, we also enter the available ranges of $F_{p}$ versus $B$ for various superconductors. ${ }^{22}$

From this plot we can estimate the practicability of reaching high fields in superconducting dipoles. The coil costs and the design complications increase with $v_{S C}$ and with $d$; in fact, one would like not to exceed $v_{S C}=10^{-3}$ by more than a factor 2 or 3 . The importance of high-current density (high $F_{p}$ ) is evident.

The bands for $\mathrm{F}_{\mathrm{p}}$ for $\mathrm{Nb}_{2} \mathrm{Sin}$ multifilament indicate material that is now available; it may be that in the future the upper limit can be raised somewhat. According to newest research, an increase of $50 \%$ for $j_{c}$ of $\mathrm{Nb}_{3} \mathrm{Sn}$ is possible; at $\mathrm{B}<7 \mathrm{~T}$, NbTi with different niobium content can produce increases up to $70 \%$ in $j_{C}$ for $5 \mathrm{~T}$ and $4.2 \mathrm{~K}$. Such improvements will be subject to questions of economy (see below).

The cost of the superconductor is

$c=v_{s c} p_{s}=8 \frac{B_{0}^{2}}{\mu_{0}} \frac{p_{s}}{F_{p}}\left(r_{i}+\frac{B_{0}^{2}}{\mu_{0} \lambda F_{p}}\right)$,

where $p_{s}$ is the price per volume of superconductor (price includes fabrication and stabilizing copper, etc.). At present, the approximate (1arge 


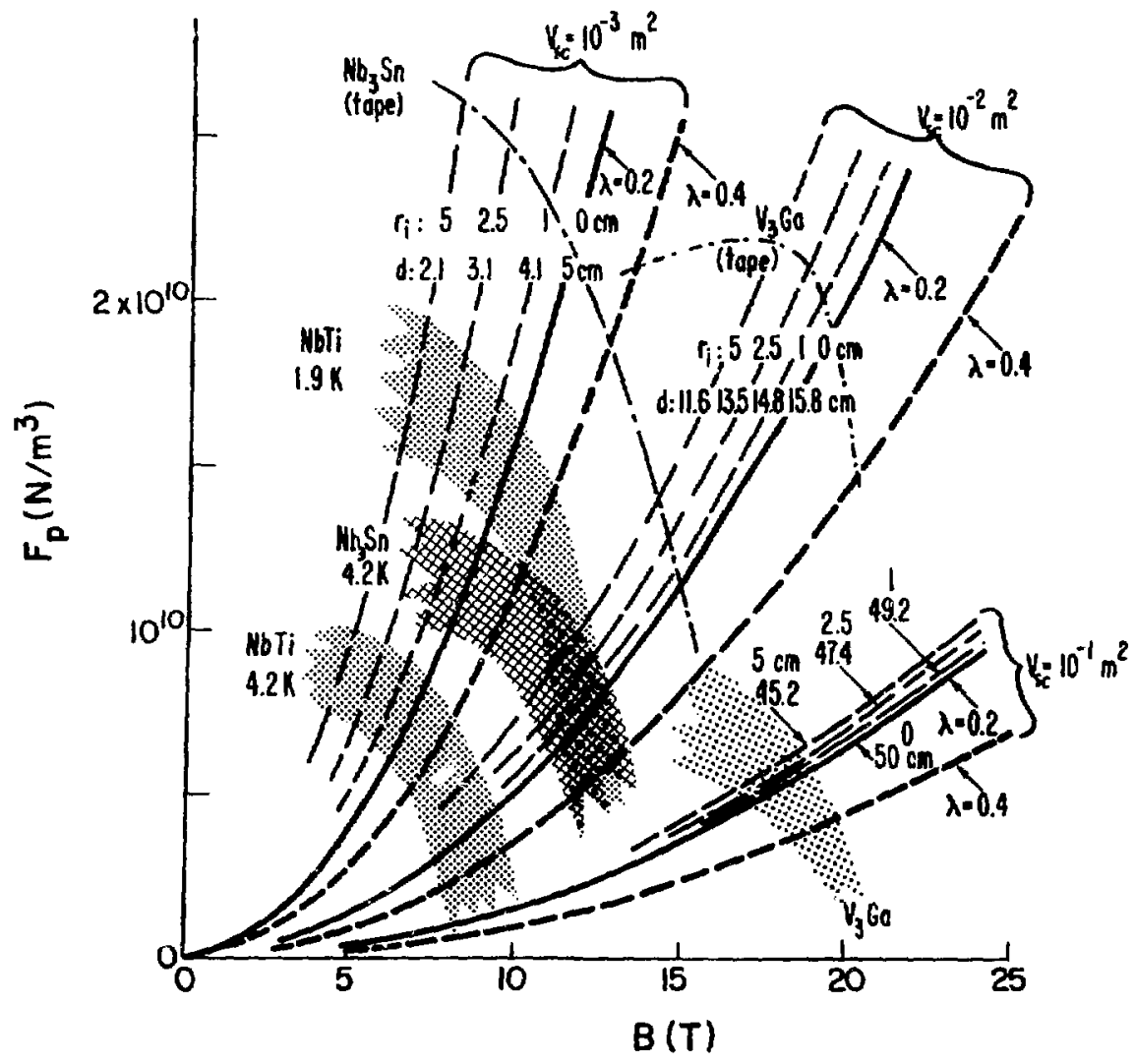

Fig. 5. HIGH DIPOLE FIELDS CAN ONLY BE REACHED WITH HIGH CURRENT DENSITYELSE THE WINDING VOLUME WILL BE PROHIBITIVE.

Superconductor flux pinning strength $F_{p}=j_{c} \times B$ versus dipole field strength of single-layer winding. The figure indicates, for three different winding sizes, the required $F_{p}$ to reach a given field $\left\langle F_{p}\right.$ is averaged over the nonstabilizer part of the superconductor). The winding sizes are characterized by the amount of superconductor needed per unit length of dipole; $y_{s c}$. A desirable winding volume corresponds to $V_{s c}=10^{-3} \mathrm{~m}^{3} / \mathrm{m} ;$ an order of magnitude larger, $V_{s c}=10^{-2} \mathrm{~m}^{3} / \mathrm{m}$ might be taken as the upper tolerable $1 \mathrm{fmit}$; another order of magnitude larger, $v_{s c}=10^{-1} \mathrm{~m}^{3} / \mathrm{m}$ is too large and too costly. The solid curves are for zero aperture and $\lambda=0.2$, according to Eq. (5). The thin dashed curves are for $\lambda=0.2$ and different apertures: $r_{i}=1,2.5$, and $5 \mathrm{~cm}$; the thick dashed curve is for $\lambda=0.4$ and zero aperture. The term $\lambda$ is the fraction of active superconductor (inciuding substrate and other nonstabilizer components required by the conductor design) in the winding cross section; the rest of the cross section is teken up by stabilizer (usually high-purity copper or aluminum), insulation, and structurol elements required by the coil design. The thickness, $d$, of the winding is given for each curve. The range of avallable multifilament conductors: $\mathrm{NbTi}^{23}$ at 4.2 and $1.9 \mathrm{~K}, \mathrm{Mb}_{3} \mathrm{Sn}^{23324}$ and $\mathrm{V}_{3} \mathrm{Ga}^{24}$ at $4.2 \mathrm{~K}$ are given by shaded areas. The two dot-dashed curves are examples of $\mathrm{Nl}_{3} \mathrm{Sn}^{25}$ and $\mathrm{V}_{3} \mathrm{Ga}^{33,26}$ tapes. 
quantity) values ${ }^{\dagger}$ of $\mathrm{p}_{\delta}$ are for $\mathrm{NbTi}, 3 \mathrm{M \$} / \mathrm{m}^{3}$; for $\mathrm{Nb}_{3}$ Sn multifilament, $5 \mathrm{M \$} / \mathrm{m}^{3}$; for $\mathrm{Nb}_{3} \mathrm{Sn}$ tape, $3 \mathrm{M} \$ / \mathrm{m}^{3}$. For easier reference: the prices of superconductor are 200, 280, and $170 \$ / 1 b$ for $\mathrm{NbTi}, \mathrm{Nb}_{3} \mathrm{Sn}$ multifilament, and $\mathrm{Nb}_{3} \mathrm{Sn}$ tape, respectively. The quoted prices are 3-5 times the cost of the raw material. t+ It could well be that with the development of large superconductor markets, not only for the SSC but also for medical instruments using magnets for Nuclear Magnetic Resonance (MMR) imaging, the prices will drop to perhaps half those quoted above, but probably not much more than half. Even with this caveat, the given prices may siill serve to illustrate, in the following, some arguments touching on economic considerations.

\section{c. Optimal Flux Pinning}

It is seen from Eq. (6) that the cost is lower for a higher value of $F_{p}$, provided the ratio $\mathrm{p}_{s} / F_{p}$ does not increase too much. For example: NbTiTa has higher $F_{p}$ values than NbTi but, tantalum being very expensive, its price is too high to be competitive. There is an optimal value for $F_{p}$.

The price $p_{s}$ of a conductor generally is dictated by the relatively high cost of raw materials (especially niobium) and depends only weakly on specific properties of the finished product. However, $p_{s}$ will depend on $F_{p}$ to the extent that special manufacturing processes are involved for achieving a higher $F_{p}$. The price of $p_{s}$ is expected to increase monotonically with $F_{p}$, starting from the lower limit set by materials and basic processing costs. Gains in $F_{p}$ by increasingiy sophisticated processing will be reflected in a higher $\mathrm{p}_{\mathrm{s}}$. There must be a limit to $F_{p}$, an ideal flux pinning, denoted by $F_{p}{ }^{*}$. As $F_{p}$ approaches $F_{p^{*}}, p_{s}$ may increase very steeply while the gain in $F_{p}$ becomes marginal. The optimial $F_{p}$ can be obtained from $E q .(6)$ by determining the cost minimum given by $d C / d F_{p}=0$. One calculates

$\frac{d C}{d F_{p}}=\frac{8 B_{o}^{2}}{\mu_{0} F_{p}}\left[\frac{d p_{s}}{d F_{p}}\left(r_{i}+\frac{B_{0}^{2}}{\mu_{0} \lambda F_{p}}\right)-\frac{p_{s}}{F_{p}}\left(r_{i}+2 \frac{B_{0}^{2}}{\mu_{0} \lambda F_{p}}\right)\right]$.

TIntermagnetics General Corporation, private communication, 1983-also, see Ref. 8.

tThe price of niobium at present is 50-90 $\$ / 1 \mathrm{~b}$, depending somewhat on the size of original stock. Density of $\mathrm{Nb}-50$ at $\% \mathrm{Ti} \approx 6.7 \mathrm{~g} / \mathrm{cm}^{3}$, of $\mathrm{Nb}_{3} \mathrm{Sn} \approx 8.0$ $\mathrm{g} / \mathrm{cm}^{3}$. 
The bracket vanishes for

$$
\frac{d p_{s}}{d F_{p}}=\frac{p_{s}}{F_{p}}\left(1+\frac{B_{0}^{2}}{\mu_{0} r_{i} \lambda F_{p}+B_{0}^{2}}\right) \text {. }
$$

One can write

$$
\frac{\Delta p_{s}}{p_{s}}=\alpha \frac{\Delta F_{p}}{F_{p}} \text {, }
$$

with $\alpha$ being the bracket term in Eq. (8). The value of $c$ can be calculated, but it is obvious that $1<\alpha<2$.

Thus, one obtains the simple rule that the dipole cost can be reduced if a flux-pinning improvenient by a certain percentage can be obtained without raising the conductor cost by more than the same percentage. If, on the other hand, the cost increase is twice that percentaqe or more, then $F_{p}$ is already above the optimum. The price versus flux-pinning relationship is summarized schematically in Fig. 6.

Considering this rule, it is questionable whether the state-of-the-art conductors indicated by the bands in Fig. 5 are not already much above their $F_{p}$ optimums. Undoubtediy, $F_{p} *$ lies well above the bands, but can it be approached any closer subject to the allowable price increases given by the above rule? For tape, the situation is different. The $F^{*}$ is much higher because neither bronze nor diffusion barriers are necessary. ${ }^{+}{ }^{+}$Tape needs a certain

TThe best sample reported in Ref. 27 consists of 2170 layers of $420 \AA$ of $\mathrm{Nb} 3 \mathrm{Sn}$ separated from each other by $90 \AA$ of $Y$, with a critical current density averaged over the $\mathrm{N}_{3} \mathrm{Sn}$ cross section of $4.3 \times 10^{10} \mathrm{~A} / \mathrm{m}^{2}$ at $6 \mathrm{~K}$ and $1 \mathrm{~T}$. From this we estimate a maximum $\mathrm{F}_{\mathrm{p}}$ (in $\mathrm{Nb}_{3} \mathrm{Sn}$ ) of $8 \times 10^{10} \mathrm{~N} / \mathrm{m}^{3}$ at $4.2 \mathrm{~K}$ and $6 \mathrm{~T}$ (keeping in mind that some of the low-field pinning comes from surface barriers that are not effective at higher fields). It is conceivable that a conductor fabricated in this manner, with 400 layers on either side of a 15- $\mu \mathrm{m}$ niobium substrate for a total thickness of $55 \mu \mathrm{m}$ (of which $34 \mu \mathrm{m}$ is Nb3Sn), would have an $\mathrm{F}_{\mathrm{p}} \max$ close to $5 \times 10^{10} \mathrm{~N} / \mathrm{m}^{3}$; in other words, considerably higher than the example given in Fig. 5. It is almost certain that such a conductor would be quite expensive and thus probably above the optimum $F_{p}$ discussed. Such high pinning values may be close to $\mathrm{F}_{\mathrm{p}^{*}}$. There are no theoretical predictions for $F_{p^{*}}$. We can estimate an upper limit by saying that the critical current density that is due to pinning should be smaller than the current density in

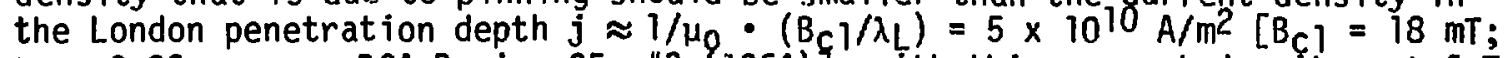
$\lambda_{L}=0.29 \mu \mathrm{m}$, see RCA Review 25, \#3 (1964) 1; with this current density, at $6 \mathrm{~T}$, there would be an $F_{p} \max \approx 3 \times 1011 \mathrm{~N} / \mathrm{m}^{3}$. 


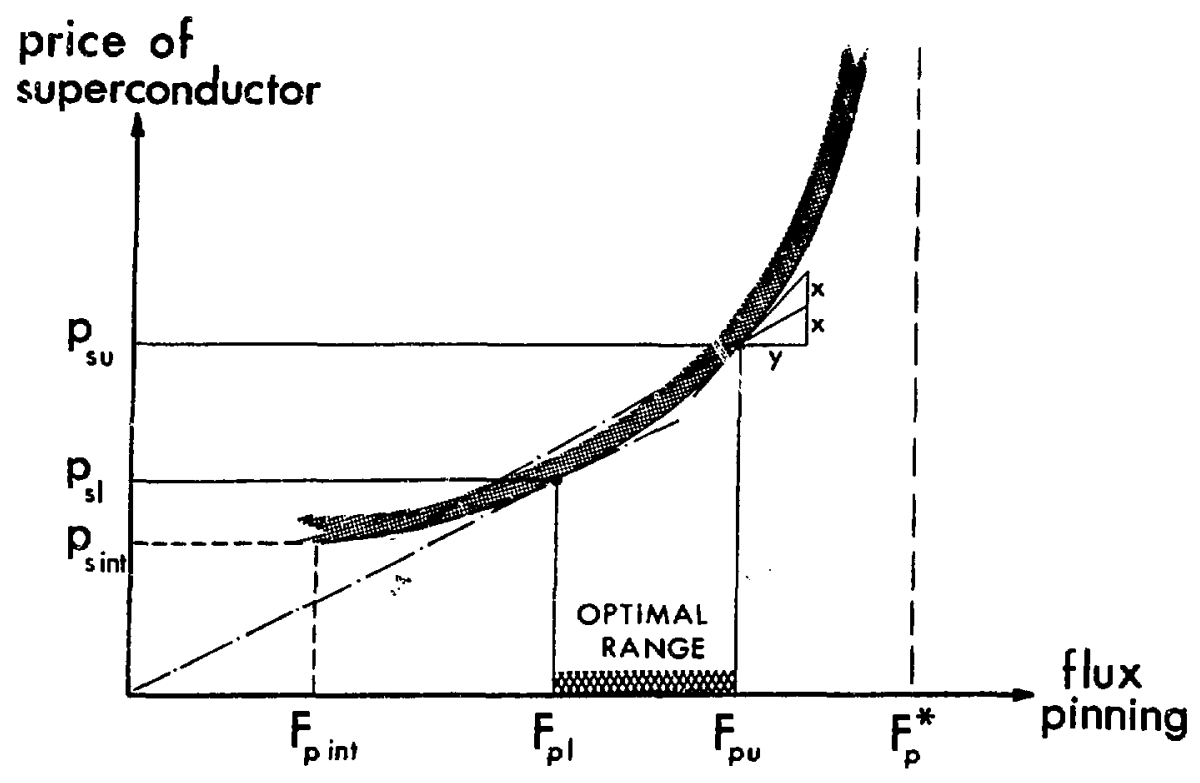

Fig. 6. FOR A SUPERCONDUCTOR, TO BE USED IN AN ACCELERATOR DIPOLE MAGNET, THERE IS AN OPTIMAL FLUX PINNING STRENGTH.

For a conductor, manufactured from a given superconducting material, there is an optimal (most economical) value for flux pinning, given by Eq. (8). The illustration represents a schematic plot of superconductor price versus flux pinning. The optimal range for $F_{p}$ is between $F_{p l}$ given by $\partial p_{s} / \partial F_{p}=p_{s} / F_{p}$ and $F_{p u}$ given by $\partial p_{s} / \partial F_{p}=2 p_{s} / F_{p}$. Correspondir.gly, there is a lowest sensible price $p_{s l}$ and a highest sensible price $p_{s u}$. This means that below the optimal range, the cost of dipoles (for whatever $B_{0}$ ) can be lowered if $F_{p}$ (and $p_{s}$ correspondingly) is raised; whereas, above the optimal range the dipole cost is lowered if $p_{s}$ is lowered. The optimal range lies somewhere between $F_{p}$ int and $F_{n}{ }^{*} ; F_{p}{ }^{*}$ is an ideal, highest flux pinning value pcssible in a given material, and $F_{p}$ int is a lower, intrinsic limit, obtained without trying. Neither $F_{p}{ }^{*}$ nor $F_{p}$ int is well defined or established either theoretically or experimentally. (Strictly speaking, to produce material with $F_{p}<F_{p}$ int would require a special effort, increasing $p_{s}$ again. $F_{p}$ int is therefore defined by a minimum in $p_{s_{s}}$ )

Note: $p_{s}$ versus $F_{p}$ plots are not usually available and, with the general volatility of superconductor prices, cannot be constructed from manufacturers price 1ists; but a manufacturer, pushed to increase the pinning strength of his product, may well be able to supply the necessary information. 
amount of (unreacted) substrate, mainly for mechanical qualities such as sufficient strength to survive the winding process. It is possible that the given $F_{p}$ values in Fig. 5 are still below optimal.

\section{Comparison of Different (Single-Layer) 10-T Dipoles}

The difference in $\mathrm{p}_{\mathrm{s}}$ between $\mathrm{Nb}_{3} \mathrm{Sn}$ multifilament and tape is entirely due to the difference in processing; the distinction is further enhanced in the values for $p_{s} / F_{p}$.

Among available conductors the approximate (large-quantity) values for $p_{s} / F_{p}$ are listed below.

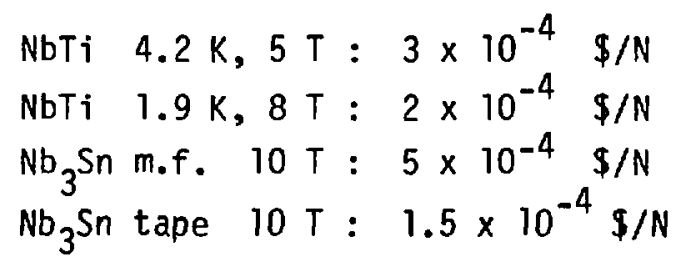

(The cost unit $\$ / N$ indicates that the job of the magnet windings is to restrain the Maxwell tensor of the produced field.)

Manufacturers often give the conductor price $p_{c}$ in $\$ / k A \cdot m$ at a given field B. Multiplying $\mathrm{p}_{\mathrm{C}}$ by $j_{\mathrm{c}}$ (critical current density in the noncopper cross section of the conductor, in $\mathrm{kA} / \mathrm{m}^{2}$ ) one obtains $\mathrm{p}_{\mathrm{s}}$ in $\$ / \mathrm{m}^{3}$; dividing by $B$ [T] gives $p_{s} / F_{p}$ in $\$ / k N$.

Table I shows what can be expected for single-layer dipoles with $\lambda=0 . ?$ and $r_{i}=2.5 \mathrm{~cm}$. (For $\lambda=0.4$, the superconductor cost for $10 \mathrm{~T}$ will be approximately $30 \%$ lower.) 
TABLE I. SINGLE-LAYER DIPOLES WITH DIFFERENT SUPERCONDUCTORS

\begin{tabular}{|c|c|c|c|}
\hline Material & $\begin{array}{c}\text { Field for } \\
\mathrm{V}_{\mathrm{sc}}=10^{-3} \mathrm{~m}^{2} \\
\text { from Fig. 5) } \\
{[\mathrm{T}]}\end{array}$ & $\begin{array}{c}\mathrm{V}_{\mathrm{sc}} \text { for } 10 \mathrm{~T} \\
\text { (from Eq. 5) } \\
{\left[\mathrm{m}^{2}\right]}\end{array}$ & $\begin{array}{c}\text { Cost of } \\
\text { Superconductor } \\
\text { for } 10 \mathrm{~T} \\
{[\mathrm{k} \$ / \mathrm{m}]}\end{array}$ \\
\hline Best $\mathrm{Nb}_{3}$ Sn m.f. & 7 & $2.9 \times 10^{-3}$ & 15 \\
Best NbTi, 4.2 K & 6 & $2 \times 10^{-2}$ & 60 \\
$1.8 \mathrm{~K}$ & 8.5 & $1.9 \times 10^{-3}$ & 6 \\
$\mathrm{Nb}_{3} \mathrm{Sn} \mathrm{tape}$ & 10 & $10^{-3}$ & 3 \\
\hline
\end{tabular}

The examples show clearly that there is a great attraction to using $\mathrm{Nb}_{3} \mathrm{Sn}$ tape if possible.

The following argument indicates that single-layer coils in the above examples are overdesigned. The bursting force in a 10-T dipole of $2 r_{i}=5-\mathrm{cm}$ aperture is approximately $5 \mathrm{MN} / \mathrm{m}$; for the containment, the superconductor has to hold twice that amount, that is, $10 \mathrm{MN} / \mathrm{m}$. From the prices, we see that we pay for $20 \mathrm{MN} / \mathrm{m}$ or more. Because the whole winding is dimensioned for the maximum field $B_{0}$, although much of it is at a much lower field, more superconductor is used than necessary. The actual dipoie design would have two or more layers rather than a single one as in the above formula for a first approximation.

\section{E. Dipoles with Several Layers}

The winding space is subdivided into $n$ layers. Counting the layers, starting from the outermost, Layer 1 is between $r_{0}$ and $r_{1}$ and Layer $k$ is between $r_{k-1}$ and $r_{k}$ with $r_{n}=r_{i}$. Each layer creates a field increment $\Delta B_{k}$. The maximum field (that is, $B_{0}$ in the aperture) is the sum of all the increments. The thickness of Layer $k$ is

$r_{k-1}-r_{k}=2 \frac{\Delta B_{k} \cdot B_{k}}{\mu_{0} \lambda F_{p}\left(B_{k}\right)}$, 
where $F_{p}$ is characteristic for the superconductor in Layer $k$. (In this example, the field distribution is simplified and taken as independent of angle $\phi$. In reality, the field is larger toward the poles and smaller at the equator.) Taking the simple case where all increments $\Delta B_{k}$ are equal and $F_{p}$ the same in al1 layers, one gets

$B_{k}=k \Delta B$ and $\Delta B=\frac{B_{0}}{n}$; therefore,

$d=\sum_{k=1}^{n} r_{k-1}-r_{k}=\frac{2(\Delta B)^{2}}{\mu_{0} \lambda F_{p}} \Sigma k=\frac{B_{0}^{2}}{\mu_{0} \lambda F_{p}} \frac{n(n+1)}{n^{2}}=\frac{B_{o}^{2}}{\mu_{0} \lambda F_{p}}\left(1+\frac{1}{n}\right)$.

In the limit of large $n$, the thickness is only one-half the single-layer thickness in Eq. (3). In practice, one may reach a reduction of 0.6 or 0.7 , and $n=3$ or even $n=2$ is sufficient.

Several examples illustrate the advantages of two- or three-layer coils as presented in the following tables (II-VII). A1l (except Table VII) are taken with a conservative value of $\lambda=0.2$.

TABLE II

TWO-LAYER DIPOLE FOR 10-T, USING $\mathrm{Nb}_{3}$ Sn MULTIFILAMENT

\begin{tabular}{|l|l|l|}
\cline { 2 - 3 } \multicolumn{1}{c|}{} & Outer Layer & Inner Layer \\
\hline Material & $\mathrm{NbTi}$ & $\mathrm{Nb}_{3}$ Sn multifi1. \\
$F_{p}\left(\mathrm{~N} / \mathrm{m}^{3}\right)$ & $8 \times 10^{9}$ & $1.25 \times 10^{10}$ \\
$\Delta B(\mathrm{~T})$ & 5 & 5 \\
$\Delta r(\mathrm{~cm})$ & 2.5 & 3.2 \\
$v_{\mathrm{SC}}\left(\mathrm{m}^{3} / \mathrm{m}\right)$ & $1.39 \times 10^{-3}$ & $1.05 \times 10^{-3}$ \\
$\mathrm{p}_{\mathrm{S}}\left(\mathrm{M} \$ / \mathrm{m}^{3}\right.$ & 3 & 5 \\
$\mathrm{C}_{\mathrm{SC}}(\mathrm{K \$} / \mathrm{m})$ & 4.17 & 5.25 \\
\hline
\end{tabular}

\begin{tabular}{|l|}
\hline \multicolumn{1}{|c|}{ Total } \\
\hline$B_{0}=10 \mathrm{~T}$ \\
$r_{i}=2.5 \mathrm{~cm}$ \\
$r_{1}=5.7$ \\
$r_{0}=8.2$ \\
$V_{w}=6.1 \times 10^{-3} \mathrm{~m}^{2}$ \\
$C=9.42 \mathrm{k} \$ / \mathrm{m}$
\end{tabular}


If a $1-\mathrm{cm}$ space is made between the layers, $\mathrm{V}_{\mathrm{NbTj}}$ is increased by $15 \%$ and the total cost of superconductor increases to $10 \mathrm{k} \$ / \mathrm{m}$.

The use of $\mathrm{Nb}_{3} \mathrm{Sn}$ tape favors a thinner, outer $\mathrm{NbTi}$ layer as shown in Table III.

TABLE III

TWO-LAYER DIPOLE FOR $10 \mathrm{~T}$, USING $\mathrm{Nb}_{3} \mathrm{Sn}$ TAPE

\begin{tabular}{|c|c|c|c|}
\hline & Outer Layer & Inner Layer & Total \\
\hline Material & NbTi & $\mathrm{Nb}_{3}$ Sn tape & \\
\hline$F_{p}\left(N / m^{3}\right)$ & $8 \times 10^{3}$ & $2.3 \times 10^{10}$ & \\
\hline$\Delta B(T)$ & 4 & 6 & $\mathrm{~B}_{0}=10 \mathrm{~T}$ \\
\hline$\Delta r(\mathrm{~cm})$ & 1.59 & 2.07 & $r_{i}=2.5 \mathrm{~cm}$ \\
\hline$V_{\mathrm{cr}}\left(\mathrm{m}^{3} / \mathrm{m}\right)$ & $6.9 \times 10^{-4}$ & $6.0 \times 10^{-4}$ & $\begin{array}{l}r_{1}=4.6 \\
r_{0}=6.2\end{array}$ \\
\hline $\mathrm{p}_{\mathrm{s}}^{\mathrm{sc}}\left(\mathrm{m} \$ / \mathrm{m}^{3}\right)$ & 3 & 3 & $v_{w}=1.0 \times 10^{-2} \mathrm{~m}^{2}$ \\
\hline$c(\mathrm{k} \$ / \mathrm{m})$ & 2.1 & 1.8 & $c=3.9 \mathrm{ks} / \mathrm{m}$ \\
\hline
\end{tabular}

The cost is furtiner reduced by increasing the field step of the inner layer (Table IV).

\section{TABLE IV}

TWO-LAYER DIPOLE FOR $10 \mathrm{~T}$, USING THICKER INNER LAYER (MATERIALS SAME AS IN TABLE III)

\begin{tabular}{|l|c|c|}
\cline { 2 - 3 } \multicolumn{1}{c|}{} & Outer Layer & Inner Layer \\
\hline$\Delta \mathrm{B}(\mathrm{T})$ & 3.5 & 6.5 \\
$\Delta r(\mathrm{~cm})$ & 1.22 & 2.25 \\
& & \\
& & \\
$\mathrm{C}(\mathrm{k} \$ / \mathrm{m})$ & 1.6 & 1.95 \\
\hline
\end{tabular}

\begin{tabular}{|l}
\hline Total \\
\hline$B_{0}=10 \mathrm{~T}$ \\
$r_{i}=2.5 \mathrm{~cm}$ \\
$r_{1}=4.75$ \\
$r_{0}=6.0$ \\
$V_{W}=9.35 \times 10^{-3} \mathrm{~m}^{2}$ \\
$C=3.55 \mathrm{k} \$ / \mathrm{m}$
\end{tabular}


A single-layer $\mathrm{Nb}_{3} \mathrm{Sn}$ tape coil is still cheaper (according to Tabie I) with regard to superconductor cost because of the higher $F_{p}$, but complications with the ends may preverit the realization of such single-layer 10-T dipoles. Two-layer NbTi dipoles at $1.8 \mathrm{~K}$ also look attractive (Table $\mathrm{V}$ ).

\section{TABLE V}

TWO-LAYER DIPOLE FOR $10 \mathrm{~T}$, USING NBTi AT $1.8 \mathrm{~K}$

\begin{tabular}{|c|c|c|c|}
\hline & Outer Layer & Inner Layer & Total \\
\hline $\begin{array}{l}\text { Material } \\
F_{p}(\text { at } 1.8 \mathrm{~K}) \\
\Delta r(\mathrm{~cm}) \\
v_{\mathrm{sc}}\left(\mathrm{m}^{3} / \mathrm{m}\right) \\
\mathrm{p}_{\mathrm{s}}\left(\mathrm{M} \$ / \mathrm{m}^{3}\right)\end{array}$ & $\begin{array}{l}\text { NbTi } \\
2 \times 10^{10} \\
1.0 \\
4.32 \times 10^{-4} \\
3\end{array}$ & $\begin{array}{l}\text { NbTi } \\
1.65 \times 10^{10} \\
2.4 \\
7.1 \times 10^{-4} \\
1.14 \times 10^{-3}\end{array}$ & $\left\{\begin{array}{l}B_{0}=10 \mathrm{~T} \\
r_{i}=2.5 \mathrm{~cm} \\
r_{1}=4.9 \\
r_{0}=5.9 \\
v_{w}=8.97 \times 10^{-3} \mathrm{~m}^{2} \\
c=3.4 \mathrm{k} \$ / \mathrm{m}\end{array}\right.$ \\
\hline
\end{tabular}

Using tapes, one may get to much higher fields, as the example with a three-layer 18-T dipole demonstrates. (Note a smaller aperture $r_{i}=2.0 \mathrm{~cm}$, Table VI.) 


\section{TABLE VI}

EXAMPLE OF $\dot{A}$ THREE-LAYER DIPOLE FOR $18 \mathrm{~T}(\lambda=0.2)$

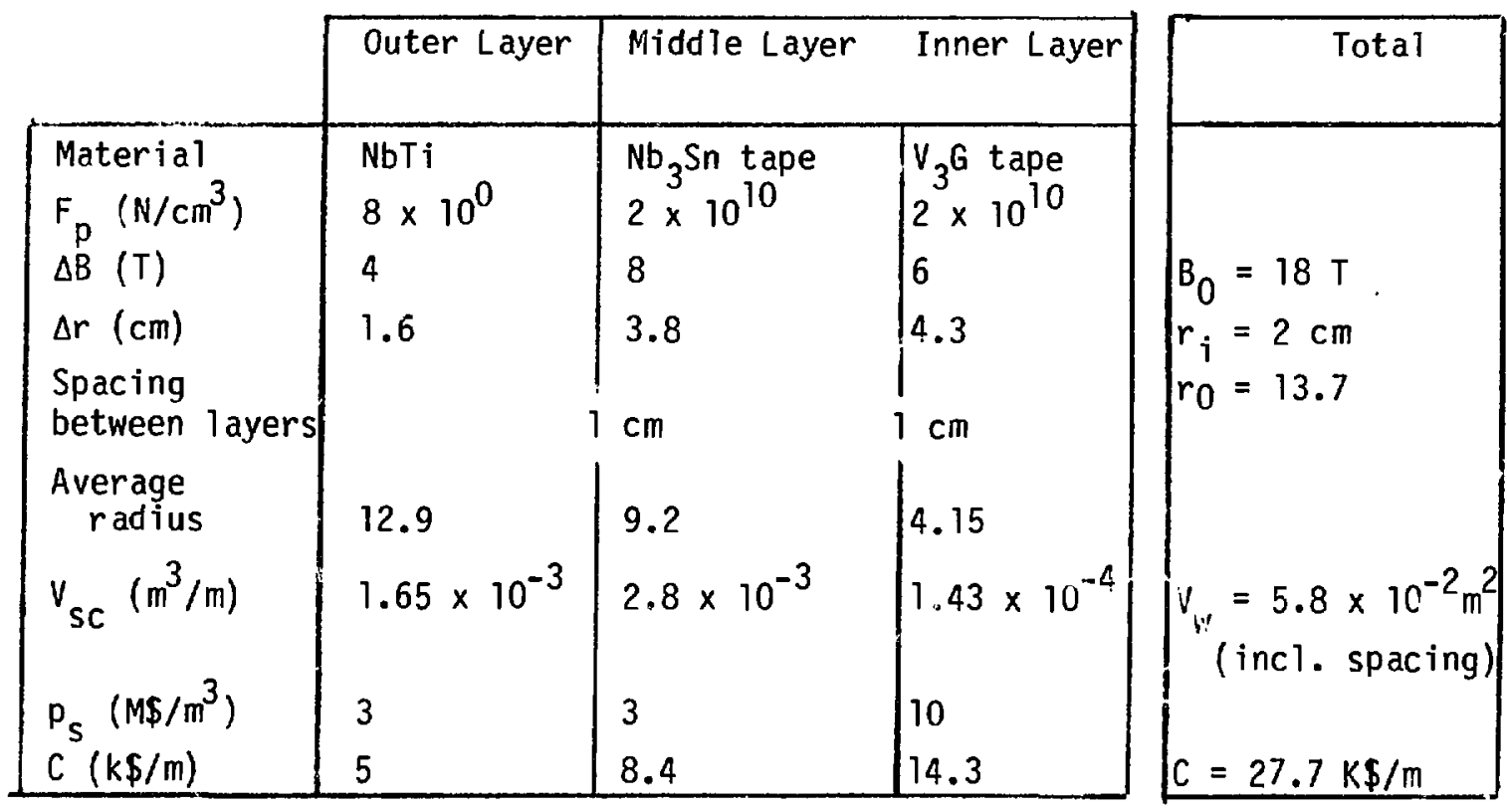

The same example with $\lambda=1 / 3$ shows substantial savings (Table VII).

\section{TABLE VII}

THREE-LAYER DIPOLE AS IN TABLE VI, BUT WITH $\lambda=0.33$

\begin{tabular}{|c|c|c|c|c|}
\hline & Outer Layer & Middle Layer & Inner Layer & Total \\
\hline$\Delta r(\mathrm{~cm})$ & 1 & 2.3 & 2.6 & $r_{j}=2 \mathrm{~cm}$ \\
\hline Spacing & & 1 & & $r_{0}=9.9$ \\
\hline Average & & & & \\
\hline radius & 9.4 & 6.75 & 3.3 & \\
\hline $\begin{array}{l}v_{s c}\left(m^{3} / m\right) \\
c(k \$ / m)\end{array}$ & $\begin{array}{l}1.25 \times 10^{-3} \\
3.8\end{array}$ & $\begin{array}{l}2.07 \times 10^{-3} \\
6.2\end{array}$ & $\begin{array}{l}1.14 \times 10^{-3} \\
11.4\end{array}$ & $\begin{array}{l}v_{w}=2.95 \times 10^{.02} \mathrm{~m}^{2} \\
c^{2}=21.4 \mathrm{kS} / \mathrm{m}\end{array}$ \\
\hline
\end{tabular}


In spite of the high price of $\mathrm{V}_{3} \mathrm{Ga}$, the specific cost $1.2 \mathrm{~K} \$ / \mathrm{T} \cdot \mathrm{m}$ is comparable to the example shown in Table II $(0.94 \mathrm{~K} \$ / \mathrm{T} \cdot \mathrm{m})$. The actual dipole cost is expected to be higher because of structure cost that would scale with $B^{2}$; a smaller aperture might compensate for this.

A discussion concerning the cost of aperture for an SSC is given elsewhere. ${ }^{28}$

\section{F. Summary}

At present, $\mathrm{NbTi}$ at $1.8 \mathrm{~K}$ or $\mathrm{Nb}_{3} \mathrm{Sn}$ multifilament at $4.2 \mathrm{~K}$ are the two options available to be explored for obtaining high-field magnets. Both have characteristic, aggravating engineering problems that will be difficult to overcome. For $\mathrm{NbTi}$, it is the small stability margin; for $\mathrm{Nb}_{3} \mathrm{Sn}$, the brittleness that necessitates either the wind-and-react technique or large bending radii at the dipole ends. Both methods are limited to fields not much higher than $10 \mathrm{~T}$. Both have relatively high superconductor costs; the chances to lower coil costs by improving critical current density of the multifilamentary materials are not good. Conductors with higher current density or flux pinning force are only interesting from an economical point of view if $p_{s} / F_{p}$ is lower than for $\mathrm{NbTi}$ or $\mathrm{Nb}_{3} \mathrm{Sn}$; this is not the case for multifilamentary $\mathrm{V}_{3} \mathrm{Ga}$ or ternary alloys and compounds, but is evident for tape conductors.

Superconductors in tape form have superior critical current densities and lower price compared to the multifilamentary form. If they can be used in the construction of serviceable accelerator dipoles, the advantages with regard to upper field limits and economy are very attractive indeed. The $\mathrm{Nb}_{3} \mathrm{Sn}$ tape and, for $12 \mathrm{~T}<\mathrm{B}<18 \mathrm{~T}, \mathrm{~V}_{3} \mathrm{Ga}$ tape are commercially available. Perhaps other materials such as $\mathrm{Nb}_{3} \mathrm{Al}, \mathrm{Nb}_{3} \mathrm{Ge},{ }^{29}$ or $\mathrm{NbN}^{30}$ could also be developed into promising options once the usefulness and need for tape is established.

\section{PAST EFFORTS (Historical Summary)}

Interest of the high-eneray community in superconducting R\&D for applications to accelerators dates back to the early 60s. P. F. Smith at Rutherford Lab suggested a superconducting upgrade to $50 \mathrm{GeV}$ for NIMROD. ${ }^{31}$ Brookhaven National Laboratory (BNL), among the pioneers of superconductivity R\&D, convened the first Applied Superconductivity Conference ${ }^{32}$ in 1967 and, in 1968, the widely attended Summer Study on Superconducting Devices and Accelerators. ${ }^{3}$ 
From studies for SPS 1-TeV upgrade at CERN and for FNAL saver/doubler emerged the very challenging goals for accelerator dipoles: 4-5 $\mathrm{T}$ in 3-4 $\mathrm{s}$, very small ac losses, toierable coil degradation and training, highly exacting field quality. ${ }^{34}$ This stimulated the development of multifilamentary superconductors, researched at Rutherford Laboratory and first manufactured in collaboration with English industry. ${ }^{35}$ FNAL developed successful magnets for the Tevatron, using "Rutherford" cable. Although the superconducting upgrade of SPS was cancelled, European activity continued. Rutherford Laboratory maintained a first-rate R\&D effort through most of the $70 \mathrm{~s}$; the quality of that research is well reflected in a recent book by M. N. Wilson. ${ }^{22}$ At Saclay emerged the now leading group for supercondicting applications in high-energy physics. Meanwhile, BNL maintained its R\&D and developed a braid conductor for accelerator magnets, but the ISABELLE project later had to abandon the braid conductor and also had to adopt a Rutherford cable with FNAL-inspired engineering design. ${ }^{36}$

The FNAL Tevatron is the first superconducting accelerator. ${ }^{37}$ other projects, also using technology closely similar to the one developed at FNAL, are HERA in Germany, 6 UNK in Russia, ${ }^{38}$ and TRISTAN in Japan. ${ }^{39}$ There is no doubt that established technology can provide 5-T magnets on the basis of multifilamentary NbTi Rutherford cable.

The present situation, compared to the one at the start of the FNAL Tevatron magnet development, has changed for the better in several respects. There are new boundary conditions: the ramp rate is one to two orders of magnitude lower, so that ac losses have become a minor problem; the apertures are much smaller, and higher current densities in the windings have become more attractive. There also are improved tools concerning field calculations, and now there is a far better understanding of superconducting coil stability.

With regard to superconducting tape, the situation is different. Some new materials, notably $\mathrm{Nb}_{3} \mathrm{Ge}$, have been found with very attractive critical properties but no prospect for being produced in multifilamentary form. However, for magnet applications multifilamentary conductor is so much superior that, since its introduction, the older tape conductor has only been used in very exceptional cases. The notable exceptions are inserts for highest field solenoids, the record holder being a 17.5-T coil in Japan. ${ }^{40}$ Most other tape coil projects ceased about 10 years ago and further development has been stagnating since. Incidentally, R\&D on one of the last tape coil projects ${ }^{4}$ 
led to the introduction of the Minimum Propagating Zone (MPZ) and to early advances in the understanding of coil stability. ${ }^{42}$ To the author's knowledye, there has never been a serious effort to use tape for accelerator magnets. ${ }^{\dagger}$

The only important application of superconducting tapes during the last decade was the superconducting ac transmission 1 ine developed at BNL. ${ }^{44}$ In the course of this work, $\mathrm{Nb}_{3} \mathrm{Sn}$ tape of superior critical current density was developed ${ }^{25}$ and manufactured by IGC. ${ }^{+\dagger}$ Thus, we are fortunate that the basic ingredient for the success of this concept, namely tape conductor of sufficient quality, already exists. It is also gratifying to salvage one of the positive results of the transmission-line project.

Looking into the future there is no doubt that progress lies in the direction of higher fields. Figure 7 is a plot of the dipole field levels of synchrotrons versus their construction date (similar to the Livingston plot for energies). The trend is unmistakable.

\section{PROBLEMS TO BE ADDRESSED AND POSSIBLE SOLUTIONS}

The goal of the concept presented in this report is to develop a highfield dipole suitable for high-energy accelerators by making use of superconducting tape conductors. The chief attractive features of using tape were explained in Sec. III. These features are high value of $F_{p}$ and low value of $\mathrm{p}_{\mathrm{s}} / \mathrm{F}_{\mathrm{p}}$ (leading to a compact, relatively inexpensive dipole winding structure) and promise to be able to reach very high fields with presently available conductors.

\footnotetext{
TThere is a related development of some interest (see Ref. 43). Tubes are formed of passive (that is, without external current feeds) coils wound from Nb3Sn tape and having dipole geometry. They were originally conceived to shield the particle path into the BEBC bubble chamber from the fringe fields caused by the return flux of the main bubble chamber field. Recently, similar structures were reported to have been used to trap 4- to 5-T dipole fields in persistent mode. See CERN Courier, 20, 345-46 (Nov. 1980) and W. Witzeling, Cryogenics 16, 29-32 (1976).

t+Intermagnetics General Corp., P.0. Box 566, Guilderland, NY 12084.
} 


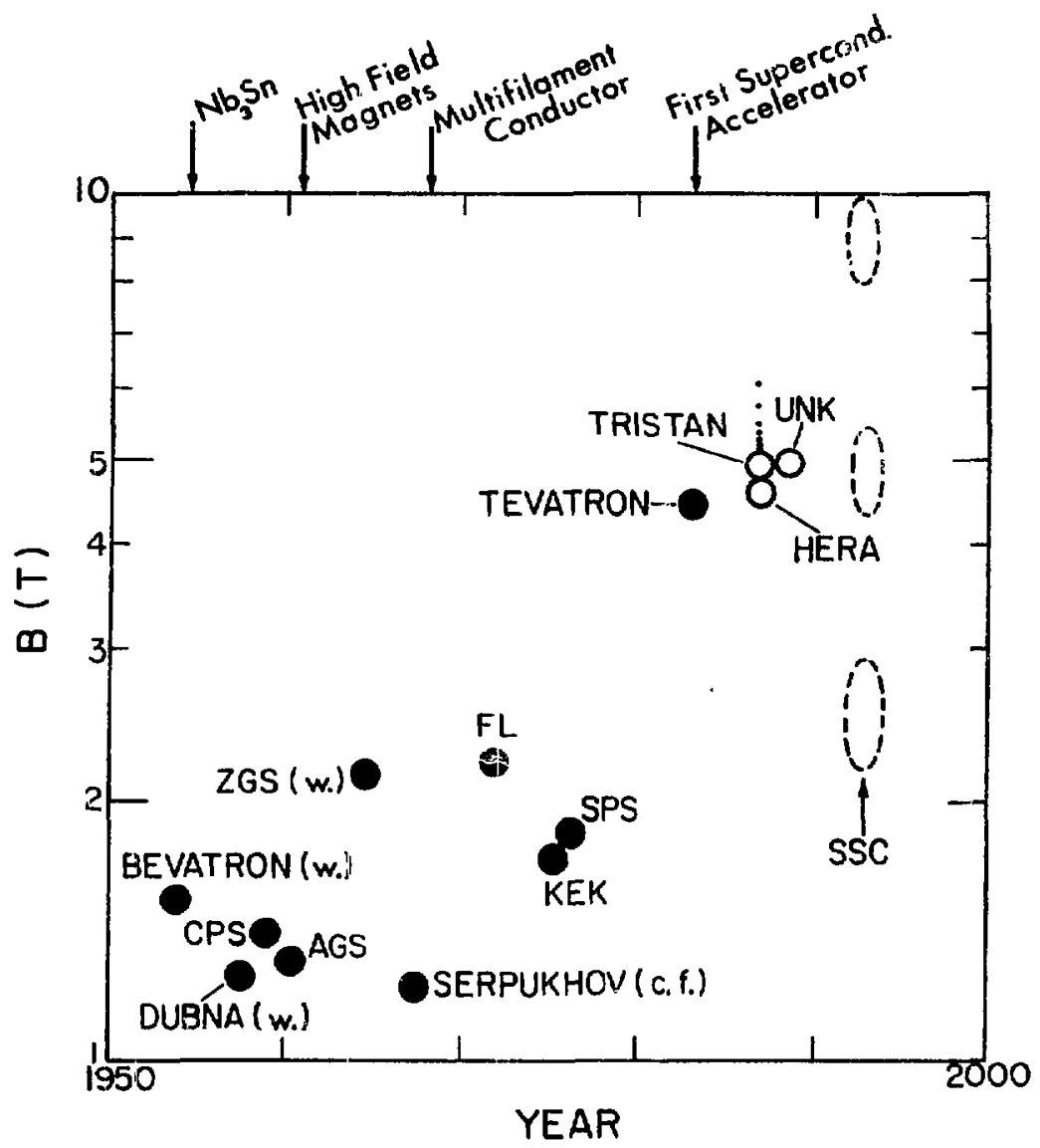

Fig. 7. THE FUTURE DEMANDS HIGH-FIELD DIPOLES.

The bending field strength of various existing and projected accelerators versus their construction year.

For UNK see Ref. 38. The bending field for the next TRISTAil phase is still open (6 $T$ would allow a 400-GeV proton ring in the present tunnel) and will depend on the success of the Japanese high-field R\&D program presently pursued at KEK. See Ref. 10, 14, 39.

Milestones of high-field superconductivity indicate the time span required for R\&D leading to a mature technology. The first multifilament conductor (NbTi) indicates the start of accelerator dipole R\&D. The first $\mathrm{Nb}_{3} \mathrm{Sn}$ multifilament conductor dates from 1971 - even now, $\mathrm{Nb}_{3} \mathrm{Sn}$ multifflament conductors are not yet established in technical applications. (For a review of superconductivity with historical emphasis, see Ref. 45.) 
The problems will be concerned with finding a suitable winding design. The attributes necessary for use in accelerators are listed below.

- high field ${ }^{+}$

- good field quality

- acceptable ramp rate (preferably with good field quality at all fields ${ }^{\dagger}$ )

- low ac loss

- no fatigue problemst (over lifetime of accelerator, that is, 30 years)

- high reliability (protection)

\section{A. Stability and Degradation}

High magnetic field implies the necessity of high current density $j=\lambda j_{c}$ in the winding. One defines $\lambda=j / j_{C}=d_{s} A_{S} / A$ where $A_{S}$ is the cross section of the actual superconductor (including bronze and other metallurgically necessary metals but without stabilizing copper), $A$ is the total cross section of the winding, and $d_{s}=j_{s} / j_{c}$ gives the fraction of the short sample critical current density $j_{c}$ that is reliably obtained in the wound conductor. The value of $\lambda$ that $c$ an be reached (that is, the necessary stabilizer, and $d_{s}$ ) will be governed by stability considerations. In high-current-density magnets, it is a question of balancing disturbances against the MPZ, 42 In a magnet design, one aims both for small disturbances and for large MPZ.

Disturbances are caused by motion of magnetic flux within the conductor and by mechanical motion of the conductor. For tape conductor, the flux motion as flux jump will be the most severe source of disturbances. It can be avoided by arranging the face of the tapes parallel to the field. The alignment has to be good enough that the field component perpendicular to the tape does not exceed approximately $0.3 \mathrm{~T}$. At $B=10 \mathrm{~T}$, this implies that the angle between tape and field should not exceed $\pm 7^{\circ} 30^{\prime}$. Such an alignment is easy to achieve in the long section of the dipole where the field geometry is two-dimensional and the tape can be tilted for perfect orientation. It may be difficult at the ends, where the geometry is three-dimensional and the tape alignment has

FThe forces, increasing with $B^{2}$ will have a serious influence on these qualities. 
to conform to the geometry required by the curvature of the winding that is necessary to cross over the accelerator tube. In a two-layer design with only the inner layer wound with tape, the ends of the tape layer are formed beyond the ends of the cuter layer, that is, in a region where the fields are lower. There are three methods to influence the relative alignments of tape face and magnetic fields:

(1) the positioning of the curved windings (subject to the constraint of forming a crossover),

(2) the positioning of ferromagnetic material (trying to form mirror image of the winding), and

(3) the positioning of superconducting material (extra tape interspersed between the tapes of the winding to force the fields to be parallel by means of induced currents).

The basic idea for Methods 2 and 3 is to shape the fields by currents induced outside the original, field-producing conductor. Iron placed above and below the windings, with iron surfaces perperidicular to the tape faces, forms images of the winding (with the current flowing in the same direction) and thus reduces the flux components at right angles to the tapes. Even above saturation fields of the iron, this mechanism still works, though with reduced efficacy. Passive superconducting tape between the windings will oppose any perpendicular field component by means of induced currents. The tape forming the current-carrying winding has the same tendency but, because of its transport current load, is much closer to criticality and cannot sustain iarge additional induced currents without suffering flux jumps as mentioned earlier.

The opportunity to employ these mechanisms in the end regions of the dipoles is given by relaxing the demands for highest current density and for highest quality of the dipole fields in the beam pipe. Such relaxing is possible because the end regions are only a small fraction of the total dipole length. High current density and high field quality are overriding considerations in the two-dimensionai regions of the dipoles.

Functioning end configurations are the greatest challenge in constructing tape-wound dipoles.

Once the flux-jump danger is overcome, it is relatively simple to guard against disturbances caused by motion. Because the fields are parallel to the 
tapes everywhere, the Lorentz forces will be perpendicular-thus el iminating the danger of sliding friction between tapes. A tape stack has a higher mechanical integrity than a winding of Rutherford cable or of braid. It is expected, therefore, that $d_{s}>90 \%$ can be reliably reached. There is a further advantage: the winding may not need precompression, thus relieving the forceretaining structure.

There is evidence to suggest that at the $d_{s}=0.8$ level, a Nb 3 Sn tape coil can stand more than 10 times larger disturbances than a multifilament NbTi coil.41 This ratio can be further improved by making the MPZ larger. The MPZ is increased by reducing the thermal resistance between tapes; for this purpose, a thin anodized aluminum tape may be the most suitable insulator between tapes.

In presently available tapes, the stabilizer is usually copper. In the case of high field windings, an aluminum stabilizer would be preferable because of the smaller magnetoresistance. ${ }^{46}$ Example: The residual resistivity of copper, $10-25 \mathrm{n} \Omega \mathrm{cm}$, increases to $60-75 \mathrm{n} \Omega \mathrm{cm}$ for $B=10 \mathrm{~T}$ and to $80-100 \mathrm{n} \Omega \mathrm{cm}$ for $B=15 \mathrm{~T}$. For aluminum, the figures are 3-10 $\mathrm{n} \Omega \mathrm{cm}$, increasing to 12-30 $\mathrm{n} \Omega \mathrm{cm}$ for $B=10 \mathrm{~T}$ and to $13-35 \mathrm{n} \Omega \mathrm{cm}$ for $B=15 \mathrm{~T}$. Resistivity is not the only consideration, however; the higher the purity of aluminum, the lower not only its resistivity but also its yield strength. Because the high-field regions also need high mechanical strength generally, the optimal dipole design will depend on a careful compromise between low resistivity and sufficient yield strength.

\section{B. Field Quality}

The field quality depends on the current distribution within the winding, that is, on both the location of the conductors and on the current distribution within the conductors.

If it is a matter of achieving field qua' ity at the highest field only, there are the following means of reaching the goal.

- Correction windings and correction currents

- Make proper allowance in the design for deformation that is due to Lorentz forces so that the conductor location is correct when the field has reached its maximum design value 
- A suitable ramp program, because it can affect the current distribution in the conductor itself. (For example, difference in ranp rate between inner and outer layer of two-layer coil; even controlled-temperature changes during ramp can be considered if necessary.)

It is unlikaly that correction windi..gs alone can overcome large defects in field quality. ${ }^{47}$ Attention to deformation and supercurrent distribution will be important. Much work will be required, consisting both of computational and experimental tests. The current distribution in tapes is strongly affected by induced currents that are due to perpendicular field components. The tape alignment is already such that perpendicular field components are small enough to prevent flux jumps. It is likely that for good field quality, much more stringent alignment conditions will prevail. A small tape width, too, would alleviate the problem. However, other considerations favor wider tape, notably a lower number of turns to simplify fabrication of the coil and to reduce the inductance, also the transmission of force through the tape stack without danger of buckling.

When it comes to keeping the good field quality during the whisle ramp, the challenge is greater. To make proper design allowances for deformation that is due to force is harder. There are two avenues to explore. The forceretaining structure should be as stiff as possible to make the deformation smal1; however, the modulus and the extent of superconductor stabilizer are more or less fixed, and a force-retaining structure distributed in the winding space reduces the current density inadmissibly. The other possibility is to allow only deformations that do not affect the field quality. That this should be possible is seen as follows: The current distribution that produces a given field is not uniquely determined. It is known that the good field quality can be produced by a cos $\phi$ distribution or by intersecting circles or ellipses or various current block distributions. ${ }^{21}$ Looking at ellipses, one can see that the deformed structure can still form intersecting ellipses to a good approximation (of course, the $B / j$ ratio will be somewhat smaller).

\section{Force Containment}

It is usual to take the overall force with a stainless steel collar consisting of laminations. Much of this structure is stressed in bending. The 
structure for the transmission of forces will be lighter if the stresses are more in tension and compression than in bending. 48

Because the forces will be rather large, it may be necessary to reduce the maximum stress in the windings by an intermediate structure between the two (or three) layers. The compressive stress in the winding can, and probably should, be limited to between 50 and $100 \mathrm{MPa}$, (unless a large amount of prestress is necessary). Small stresses are desirable to keep the displacement of the field-producing currents small (see Sec. VI.B concerning field quality) and because of the low-yield stress of high-conductivity stabilizer, as mentioned above; furthermore, thin insulation, such as Kapton, has a yield strength not much above $100 \mathrm{MPa}$. The order of magnitude of the minimal stresses can be gauged by keeping in mind that the stress in a field of 10 or $15 \mathrm{~T}$ is 40 or $90 \mathrm{MPa}$, respectively, and that the accumulated stress in a winding with $\lambda F_{p}=4 \times 10^{9} \mathrm{~N} / \mathrm{m}^{3}$ amounts to $40 \mathrm{MPa}$ per centimeter of winding thickness.

The remaining problems like ac losses, fatigue, and protection will be comparatively smaller. It should be pointed out that most of the discussed problems also apply to multifilamentary windings with the exception of the end geometry and the current distribution in the conductor.

There are also advantages of the tape winding over multifilamentary windings such as mechanical integrity and easier force and heat transfer within the tape stack.

In conclusion of this section, we repeat: the problems for a dc magnet, that is, one that only has to perform at the maximum field, will be much easier to solve than those for an ac magnet, which has to perform during the whnle ramp.

\section{PROPOSED WORK AND GOALS}

The aim is to construct and test a represeniative model of a high-field dipule. To be representative, the dipole should have an aperture of $\sim 5-\mathrm{cm}$ i.d. and be long enough to have a two-dimensional field section that is not influenced by the field distoritions of the ends (ends are ti ree-dimensional field sections). The total length will be about 1.5-2 $\mathrm{m}$, with the threedimensional sections about $0.5 \mathrm{~m}$ each. 
The design should incorporate most solutions to the problems outlined in the previous section. The dipole will have two layers: the inner, high-field section wound with $\mathrm{Nb}_{3} \mathrm{Sn}$ tape, and the outer, low-field section with multifilamentary NbTi as now widely used in accelerator dipole technology. The force-retaining structure would rely more on tension and compression members, rather than $\mathrm{C}-\mathrm{clamps}$ needing high bending strength. Cooling will be with liquid helium at $4 \mathrm{~K}$.

The dipole ends will be constructed so that most, if not all, threedimensional regions (that is, all regions where conductors are to be curved) will lie in considerably lower-than-maximum fields.

A sketch of the two-dimensional cross section and of the end construction is given in Fig. 8. This conceptual design is based on rough calculations and on a cardboard model of the ends.

The first goal will be to reach an 11-7 dipole field with acceptable field quality. The ramp rate and field quality during the ramp will be of no concern in this first phase; that is, the dipole need only be capable of dc operation at the highest field.

We must also consider two important secondary goals: (1) The design must be suitable for industrial mass production; that is, most parts that will have to be machined for the model prototype should be replaced later by stamped, extruded, cast parts. (2) The testing of the model prototype must give fairly clear indication of the problems to be solved to reach acceptable ramp rates and field quality during the ramp. The dc magnet should be a stepping stone to a functional ac magnet.

Some further thought should be given to problems like differential thermal expansion between components for the future full-length dipole.

\section{A. Work to Be Done}

1. Calculations. The model dipole design will be based on careful calculations that involve some optimizations. The two-dimensional design can rely on existing codes for field and force calculations. Conductor location and tape orientation, correction windings, force structure, dimensioning and positioning of iron yoke are all interconnected and depend on the results of accurate calculations. Three-dimensional calculations will be more difficult. 


\section{CROSS SECTION}

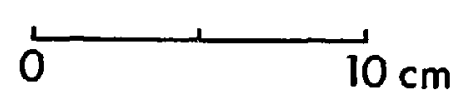

Fig. 8. CONCEPT OF DIPOLE WITH TAPE-WOUND, INNER HIGH-FIELD WINDING.

Cross section shows how tapes are aligned parallel to field and how the force structure takes the forces mostly in tension, by stainless steel bands, and in compression, by stamped stainless steel laminations (in mode! dipole: machined).

End configuration: The wide loop of the tapes ensures low fields in all areas where the windings (especially the low-field NbTi windings) have bends. 
There are three-dimensional magnet codes that will be useful, but the additional constraint of conductor placement's having to satisfy the crossover tape-bending geometry creates extra complications. The reliability of calculations will have to be tested independently.

2. Analog Modeis. It is proposed to complement three-dimensional calculations with room-temperature scale models, using copper tape, to verify field calculations and to help with the optimization of conductor placement.

3. Small-scale Tests. The crucial new concepts for obtaining workable dipole ends will need small-scaie tests with superconducting tape. Such tests must include a study of the magnetization of tape stacks and of the degradation of small tape-wound pancake and racetrack coils in external fields of up to about 5 T. Finally, small models of end geometries must be tested. These small models will be tape windings that have pretzel-like shapes.

4. Design of Model Dipole. The design will be on the basis of the optimizing calculations, analog models, and small-scale tests. The two ends can be different. The tests are to be in a standard vertical cryostat. It may be necessary to make separate tests of insulation under force, ${ }^{\dagger}$ and of stress-strain behavior of the structure before finishing the design. Also, the needed tape may not be of the standard commercially available kind and may require some development by the manufacturer.

5. Construction of Model Dipole. This is the phase where ideas and suggestions for mass production should be gathered and developed.

6. Testing of Model Dipole. There must be thermometers, voltage taps, and strain gages built into the coil to observe cool-down, quench

Fnuring 1982/1983, while at Saclay as a visiting scientist, the author made experimental tests of the heat transfer between two copper surfaces separated by Kapton. At $4.2 \mathrm{~K}$ the contact resistance saturates at approximately $2.4 \mathrm{kWm}^{-2} \mathrm{~K}-1$ per copper-Kapton interface at a contact pressure $<200 \mathrm{MPa}$. However, the thermal conductivity of Kapton was measured to be $10 \mathrm{mwm}-1 \mathrm{~K}-1$, much lower than expected and, in fact, completely dominating the thermal resistance between the two copper surfaces. (A report on these findings will be published.) 
location during training, and stress-strain behavior of the structure. Complete field measurements in the inner diameter may need a warm insert.

\section{B. R\&D Plan}

To reach the goal outlined in the previous section (a model dipole of $5 \mathrm{~cm}$ i.d., $B \geq 11 \mathrm{~T}, 1.5-2 \mathrm{~m}$ long, using $\mathrm{Nb}_{3} \mathrm{Sn}$ tape for the inner, highfield layer), a 3-year timetable is proposed in Table VIII.

The cost of the program can be estimated on the basis of Table VIII, keeping in mind that the work. may begin with only two scientists and one technician; the manpower requirement would increase about threefold for the second phase (design, construction, testing).

TABLE VIII

\section{R\&D PLAN FOR 3 YEARS}

(a) Calculations

two-dimensional three-dimens.

(b) Analog models

(c) Small-scale tests $R$ temp. field meas. procurement

REVIEW

(d) Design of 2-m model dipole

(e) Construction pretzel-coils

(f) Testing

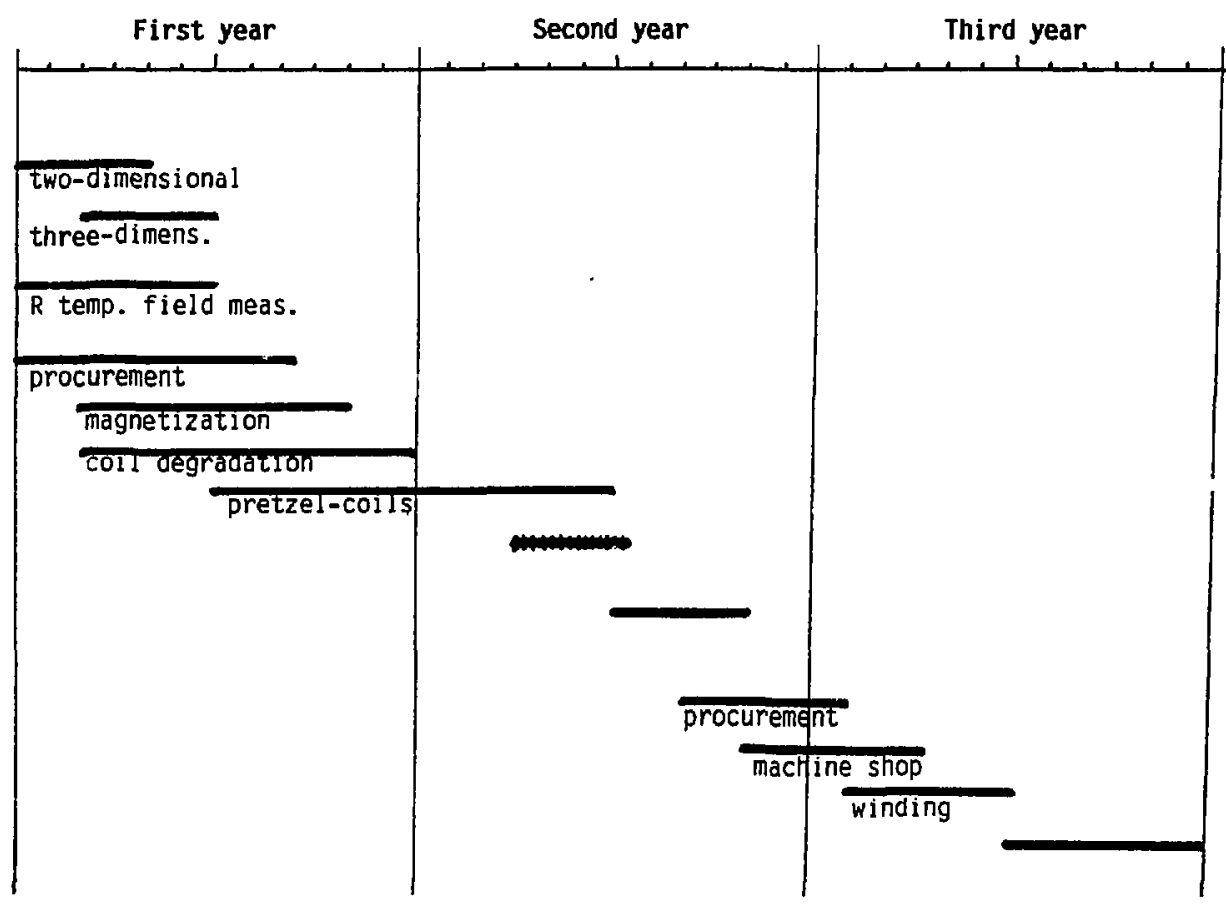




\section{OUTLOOK}

This report addresses an R\&D problem. Real research is always based on a question to which the answer is not yet known. Our general question is this: Can we reach high dipole fields suitable for accelerator bending magnets? It is already known that, for overriding reasons of economy, the windings must be superconducting and the current density must be as high as possible; also, the fields of interest are $\geq 10 \mathrm{~T}$. Therefore, we address a more specific question: Can we build an 11-T dipole magnet, making use of $\mathrm{Nb}_{3} \mathrm{Sn}$ tape conductor, that demonstrates suitability for use as accelerator bending magnet? This is the first goal.

I believe I see a way to a positive answer in two to three years, but it would not be a true question if that answer were guaranteed. Even if the answer should be negative, learning the reasons why it cannot be done would constitute progress in the field of superconducting accelerator-magnet technology. Basic problems should surface during the first year in the research phase, especially while the small-scale tests are under study. When entering the design and construction phase, the risks of failure will be small.

Success in reaching the first goal will open up great opportunities for proceeding along various avenues. Without further development a dc dipole can be used

- as a beamline bending magnet, and

- as a bending magnet in storage rings. Further development may follow along different directions.

(1) High-field dc magnets can be used in accelerators if they are combined with already developed 5-T dipoles that change during acceleration from $-5 \mathrm{~T}$, correcting for excess curvature in the dc magnets at low beam energy, to $+5 \mathrm{~T}$, for added curvature at the high energy. This new, ac-dc concept ${ }^{49}$ is possible because of the unprecedented high injection energies; it seems to be conceptually sound but would need to be developed and tested.

(2) Further R\&D on high-field tape magnets would push for dc magnets with reasonably fast ramp rate, leading to full accelerator magnets.

(3) Another development would be directed toward still higher field dc dipoles. If in a third, very high field layer, $\mathrm{V}_{3} \mathrm{Ga}$ tape (or $\mathrm{Nb}_{3} \mathrm{Ge}$ tape) were used, $B=18 \mathrm{~T}$ might be possible. 
(4) The use of high-field tape conductor in quadrupoles and in combinedfunction magnets should also be explored.

Which of these four options is to be pursued depends to a large extent on the results of the test program on a successful model dipole. The problems of achieving reasonable ramp rates and/or higher fields should be recognizable and assessable from the results and proper interpretation of the tests.

A successful high-field dipole program could open very interesting future options for an SSC. The following examples may illustrate this.

Suppose a 20-TeV SSC were designed with bending field strength between 2 and $10 \mathrm{~T}$. It would be housed in a tunnel between 200 and $50 \mathrm{~km}$ in length (see Curve $a$ in Fig. 9 that indicates bending radius versus B.) Using the same tunnel with conventional $0-$ to $5-T$ ac bending magnets, the energy indicated by Curve $b$ could be reached; with 0 - to 12.5-T ac bending magnets, the much higher energies, as in Curve $f$, could be reached. An ac-dc single ring, with $\pm 5-T$ ac magnets and 12.5-T dc magnets with injection at $1 \mathrm{TeV}$, could reach energies between 70 and $15 \mathrm{TeV}$, as in Curve c; subsequently, a second ring with more dc magnets and injection from the first ring (at energies as in Curve c) could reach energies between 100 and $20 \mathrm{TeV}$, as in Curve e. However, injecting at $20 \mathrm{TeV}$ into a single ac-dc ring, one could reach energies between 80 and $22 \mathrm{TeV}$, as in Curve d.

High-field dc dipoles can be used in storage rings. For instance, the 20-TeV beam from an SSC with conventional 5-T dipoles (36-km-diam ring) can be stored in a ring of 14-km diam with 12.5-T dc dipoles while a second beam of $20 \mathrm{TeV}$ in the opposite direction is accelerated for collision with the stored beam. Such an option may have merit when an existing facility (in this case a 14-km-diam ring) is upgraded with a larger ring having a common tangent.

A very compact version of an SSC could be accommodated in an 18-km-diam ring using the ac-dc concept. ${ }^{49}$ Stage $I$, consisting of $\pm 5-T$ ac dipoles $7 \mathrm{~m}$ long interspersed with 12.5-T dc dipoles $3.2 \mathrm{~m}$ long, can accelerate from injection at $1 \mathrm{TeV}$ to $14.5 \mathrm{TeV}$. Stage II with a length ratio $3 / 7$ of $\pm 5-\mathrm{T} / 12.5-\mathrm{T}$ dipoles accelerates from $14.5 \mathrm{TeV}$ to $20 \mathrm{TeV}$. The $20-\mathrm{TeV}$ beam can be stored in Stage II while Stage I is accelerating a $\bar{p}$ beam to $14.5 \mathrm{TeV}$, or, alternately, while the polarity of the dc dipoles in Stage $I$ is reversed for a 14.5-TeV $p$ beam in the opposite direction. Collisions of $14.5 \mathrm{TeV}$ on $20 \mathrm{TeV}$ gives $E_{c m}=34 \mathrm{TeV}$, which is quite acceptable for an SSC. 


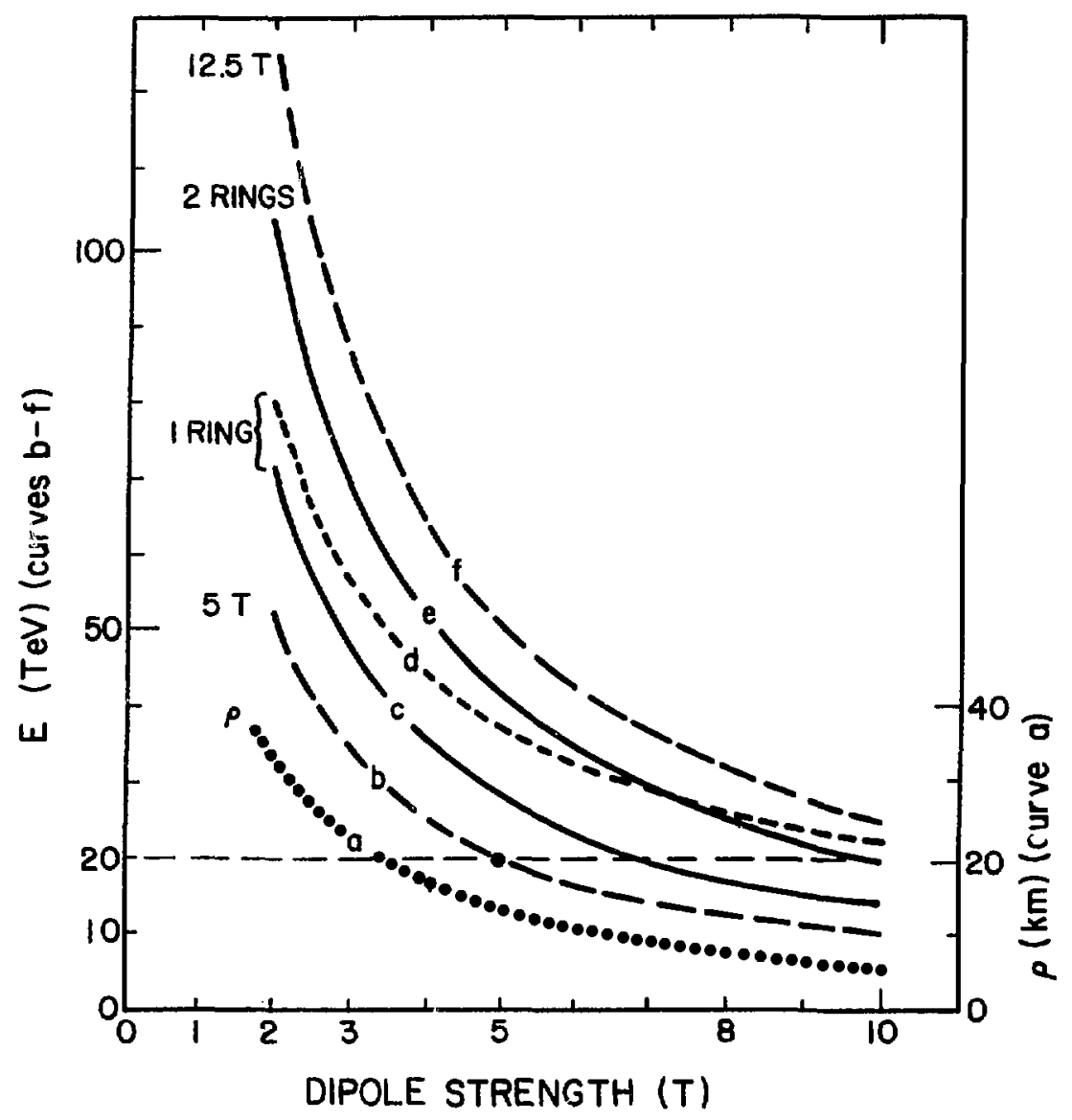

Fig. 9. A FUTURE SSC UPGRADE MAY REACH $100 \mathrm{TeV}$ IN SAME RING TUNNEL.

Curve a gives bending radius $p$ (scale on right) versus the chosen dipole strength for original 20-TeV SSC. The other curves indicate the beam energy that will be avatlable if the original ring tunnel is used with different bending magnets. Curves $b$ and $f$ for dipole magnets (used conventionally) from $B_{\min }$ at injection to $B_{\max }$ with $B_{\max } \times 5 T$ or $12.5 \mathrm{~T}$, respectively. Curves $c, d$, e for ac-dc concept, with 12.5-T dc dipoles and $\pm 5-T$ dipoles; Curve $c$ is for a single ring with injection at 1 Te.; Curve $d$ i: for a single ring with injection at $20 \mathrm{TeV}$. Curve $e$ is for two rings, the second ring being injected from the first ring, at energies given by Curve c. Example: If the original SSC is butit with superferric magnets between 2-3 T, a future upgrade with 5-T magnets can giva beam energies between 35 and $50 \mathrm{TeV}$. With high-field magnets and ac-dc concept, energies between 50 and $100 \mathrm{TeV}$ become available. 
In conclusion: The proposed activity can benefit the SSC program in several respects, depending somewhat on the time frame in which the SSC program progresses. High-field magnets may influence the primary design if start of construction is more than 6 years away; they can be considered as alternate solution if the original design should run into difficulty; they will provide options for the future. The most likely and probably the most important promise is the preparation of options for future upgrade. To reach a mature technology without a crash program may take 15 years.

\section{CONCLUSIONS}

This report has presented a concept for building accelerator dipoles with record high fields. In this new approach we want to use superconducting tape rather than multifilamentary conductor because of the potential for higher current density in the winding and also because of the availability of tape material up to fields of $20 \mathrm{~T}$.

The traditional approaches to reaching high-field dipoles include the use of $\mathrm{NbTi}$ conductors at $1.9 \mathrm{~K}$, or $\mathrm{Nb}_{3} \mathrm{Sn}$ multifilament conductors in a windand-react technique. Both approaches are severely limited in providing the necessary high-current density with adequate stability; so far, neither of these methods has been successful in reaching $10 \mathrm{~T}$. It is expected that for fields of $10 \mathrm{~T}$ and higher, superconducting tapes can give current densities more than twice as high; at the same time, their cost may be only half.

The proposed use of tapes poses peculiar problems: (a) the avoidance of flux jumps is essential for coil stability; (b) the formation of the dipole ends is more difficult than for the established state of the art with Rutherford cable as conductor. To avoid flux jumps, the tape irce must be parallel to the field throughout the winding.

Our conceptual solution envisages a high-field winding of tape conductor inside a conventional low-field winding with Rutherford cable. The end geometry is arranged so that all the bends are in low fields. Furthermore, a field parallel to the tapes in the end region is achieved by means of interleaved superconducting tape and ferromagnetic pole pieces, both passive; the method is possible because highest current densities are not essential in the end regions. 
Beginning with a demonstration of the concept's feasibility by calculations and small-scale tests, the goal of the R\&D will be to design, construct, and test a short prototype dipole of 11-T field and 5-cm clear aperture.

\section{ACKNOWLEDGMENT}

The author is thankful for several valuable comments from David C. Larbalestier.

\section{REFERENCES}

1. AIP Conference Proceedings, No. 91 "Laser Accelerator of Particles" (Los Alamos, 1982), P.J. Channel1, Ed., Am. Inst. Phys. 1982.

2. Catalogue of High-Energy Accelerators, compiled by J. H. B. Madsen and P. H. Standley, XIth Int. Conf. on High Energy Accelerators, CERN, July 1980.

3. L. M. Lederman, "Fermi lab and the Future of HEP," Proc. 1982 DPF Summer Study on Elementary Particle Physics and Future Facilities, June 28-July 16, 1982, Snowmass, Colorado, p. 125-127.

4. R. Huson, Proc. $20 \mathrm{TeV}$ Hadron Collider Technical Workshop, Cornell Univ., March 28-April 2, 1983, Apperdix IV-1 "Why Superferric Magnets for a Desertron," (14 pp.).

5. R. R. Wilson, "The Pentevac: A Site-Filling Accelerator at Fermilab," Proc. Workshop on Possibilities and Limitations of Accelerators and Detectors, Fermi National Accelerator Laboratory, October 15-21, 1978, 67-79 (1979).

R. R. Wilson, "Fantasies of Future Fermilab Facilities," Rev. Mod. Phys., 51, 259-273 (1979).

6. U. Amaldi, "European Projects in High-Energy Physics," p. 415-432, AIP Conf. Proceedings, Number 81, "Particles and Fields-1981: Testing the Standard Mode1," C. A. Heusch and W. T. Kirk, Eds., American Institute of Physics, 1982.

7. W. Hassenzahl, "Cost of High-Field $\mathrm{Nb}_{3} \mathrm{Sn}$ and NbTi Accelerator Dipole Magnets, " paper LH-14, 1982 Applied Superconductivity Conference, Knoxville, Tennessee, November 30-December 3, 1982.

8. W. Hassenzahl, "A Comparison of the Costs of Superconducting Dipoles using NbTi, Nb3Sn and NbTiTa," IEEE Trans. Nucl. Sci., NS-28, 3277-3279 (1981). 
9. K. Carta, D. Conover, C. Mathewson, L. Thompson, "SSC Tunnel Project Site Investigation," in R. Slansky, "Site Atlas for the Superconducting Super Collider, "Los Alamos National Laboratory document LA-UR-83-3078 (1983).

10. H. Brechna, E. J. Bleser, Y. P. Omitrevskiy, H. E. Fisk, G. Horlitz, J. Goyer, H. Hirabayashi, and J. Perot, "Superconducting Magnets for High Energy Accelerators," IEEE Trans. Magnetics, MAG-17, 2355-2365, September 1981.

11. A. Patoux, J. Perot, and J. M. Rifflet, "Test of New Accelerator Superconducting Dipoles Suitable for High Precision Field," IEEE Trans. Nucl. Sci., NS-30, 3681-3683 (1983). Also: G. Horlitz et al., "Performance of ... Prototype Coils for HERA," ibid p. 3390-3392.

12. C. E. Taylor, R. B. Meuser, "Prospects for $10 \mathrm{~T}$ Accelerator Dipole Magnets," IEEE Trans. Nuc1. Sci., NS-28, 3200-3204, June 1981.

13. W. Gilbert, S. Caspi, W. Hassenzahl, R. Meuser, C. Peters, J. Rechen, R. Schafer, C. Taylor, and R. Wolgast, "A 9.1-T Iron-Free Nb-Ti Dipole Magnet with Pancake Windings," IEEE Trans. Nucl. Sci., NS-30, 2578-2580 (1983).

14. H. Hirabayashi, "High Field Superconducting Magnets for Particle Accelerators," IEEE Trans. Nucl. Sci., NS-30, 3304-3308 (1983).

15. W. B. Sampson, S. Kiss, K. E. Robins, A. D. McInturff, "A Mult ifilamentary Nb3Sn Dipole Magnets," IEEE Trans. Magnetics, MAG-13, 287-289 (1977).

16. A. Asner, Ch. Becquet, D. Hagedorn, Ch. Niqueletto, and W. Thomi, "Development and Testing of High Field, High Current Density Solenoids and Magnets, Wound with Stabilized Filamentary Nb3-Sn Cable and Reacted after Winding," IEEE Trans. Magnetics, MAG-13, 416-419 (1977).

17. David C. Larbalestier, "Superconducting Materials-A Review of Recent Advances and Current Problems in Practical Materials," IEEE Trans. Magnetics, MAG-17, 1668-1686 (1981).

18. W. Schauer and F. Zimmermann, "Temperature Dependence of the Critical Current and Pinning Behavior for Nb3Sn Filamentary Superconductors," Adv. Cryogenics Eng., 26, 432-441 (1979).

19. T. Tachikawa, "Research and Development at the Japanese National Research Institute for Metals," Cryogenics, 19, 307-315 (1979).

20. R. A. Beth, "An Integral Formula for Two-Dimensional Fields," J. Appl. Phys., 38, 4689-4692 (1967).

21. M. N. Wilson, Superconducting Magnets, Chap. 3.2, (Clarendon Press, 0xford, 1983). 
22. Physics Vademecum, H. L. Anderson, Ed., Sec. 7.02, (Am. Inst. Physics, New York 1981).

23. D. C. Larbalestier, "Superconducting Materials for Particle Accelerator Magnets," IEEE Trans. Nucl. Sci., NS-30, 3299-3303 (1983).

24. K. Tachikawa, "Recent Developments in Filamentary Compound Superconductors," Adv. Cryogenic Eng., 28, 29-40 (1981).

25. P. H. Brisbin, P. S. Swartz, and K. W. Pickard, "Low AC Loss Nb3Sn

Tape for Transmission Line Applications, "IEEE Trans. Magnetics, MAG-15, $146-149(1979)$.

J. S. Cas 1 aw, "Enhancement of the Critical Current Density in NiobiumTin," Cryogenics 11, 57-59 (1971).

26. K. Tachikawa and $Y$. Iwasa, "Current Capacities of Superconducting $V_{3} G a$ Tapes in High Magnetic Fields," App1. Phys. Lett., 16, 230-231 (1970).

27. R. E. Howard, M. R. Beasley, T. H. Geballe, C. N. King, R. H. Hammond, R. H. Norton, J. R. Salem, and R. B. Zubeck, "Electrical Properties of Multilayered Nb3Sn Superconducting Power Line Conductors," IEEE Trans. Magnetics, MAG-13, 138-143 (1977).

28. S. L. Wipf, "Dipole Aperture and Superconductor Requirements," Proc. of Ann Arbor Workshop on Accel. Physics Issues for a Superconducting Super Collider, December 1983, M. Tigner, Ed., 167-170. University of Michigan report UM HE 84-1.

29. A. I. Braginski and H. C. Freyhardt, "Workshop on Superconductors for Magnets: Frontiers of Technology," IEEE Trans. Magnetics, MAG-17, 2343-2354 (1981).

J. A. Woollam, S. A. Alterovitz, E. Haugland, G. W. Webb, "Critical Currents in $A-15$ Structure Nb3Al Converted from Cold-Worked bcc Structure," App1. Phys. Lett. 36, 706-708 (1980).

M. P. Maley, L. R. Newkirk, J. D. Thompson and F. A. Valencia, "Development of Long Continuous $\mathrm{Nb}_{3} \mathrm{Ge}$ Tape Conductors with High Current Density at Elevated Temperature and Field," IEEE Trans. Magnetics, Mag-17, 533-540 (1981).

30. J. R. Gavaler, J. Greggi, R. Wilmer, "Properties of NbN Films Crystallized from the Amorphous State," IEEE Trans. Magnetics, MAG-19, $418-421$ (1983).

31. P. F. Smith, "Pulsed Superconducting Magnets and the Possibility of an Inexpensive Conversion of NIMROD to $50 \mathrm{GeV}$, Report RHEL/M90 (1965).

32. "National Superconductivity Information Meeting," Brookhaven National Laboratory report BNL 50038 (C-49), (Abstracts of papers) November 9-11, 1966. 
33. "Proceedings of the 1968 Summer Study on Superconducting Devices and Accelerators," Brookhaven National Laboratory report BNL 50155 (C-55), June 10-July 19, 1968.

34. P. F. Smith, "Superconducting Synchrotron Magnets - Present Status," Proc. 8th Int. Conf. on High-Energy Accel., CERN, Geneva, 1971, 35-45.

G. K. Green, "Superconducting Magnets in Accelerators," Proc. "Herbstschule über Anwendung der Supraleitung in Elektrotechnik und Hochenergiephysik," October 9-13, 1972, Titisee (KfZ, Karlsruhe), 01-026.

35. "Experimental and Theoretical Studies of Filamentary Superconducting Composites," Superconducting Applications Group, Rutherford Laboratory, J. Phys. D: Appl. Phys., 1970, Vol. 3, 1517-1585.

36. R. B. Palmer, N. Baggett, P. F. Dahl, "Status Reports on Isabelle Magnets," IEEE Trans. Magnetics, MAG-19, 189-194 (1983).

37. J. R. Orr, "Status of the Energy Saver," IEEE Trans. Magnetics, MAG-19, 195-197 (1983).

38. "The IHEP Accelerator-Storage Complex Status Report," (no author name) Proc. of the Workshop on Possibilities and Limitations of Accelerators and Detectors, FNAL, October 15-21, 1978 (1979), pp. 13-33.

39. T. Nishikawa, S. Ozaki and Y. Kimura, "Tristan Project and KEK Activities," Surveys in High Energy Physics, 3, 161-164 (1983).

40. W. D. Markiewicz, E. F. Mains, R. M. Vankeuren, R. E. Wilcox, C. H. Rosner, H. Inoue, C. Hayashi, and K. Tachikawa, "A 17.5 Tesla Superconducting Concentric $\mathrm{Nb}_{3} \mathrm{Sn}$ and $\mathrm{V}_{3} \mathrm{Ga}$ Magnet System," IEEE Trans. Magnetics, MAG-13 (1977).

41. A. P. Martinelli and S. L. Wipf "Investigation of Cryogenic Stability and Reliability of Operation of Nb3Sn Coils in He-Gas Environment," Proc. 1972 Appl. Supercond. Conf. IEEE Pub. No. 72CH0682-5-TABSC, 331-340; F. Fau, H. J. Jackel, A. P. Martinelli, S. L. Wipf, "On the Performance of Nb3Sn Test Coils for Levitated Multipoles, in Liquid Helium and in He-Gas up to $17 \mathrm{~K}$," ibid, p. 325-330; H. J. Jackel, J. Kisslinger, F. Rau "Performance of Medium-Sized Nb3Sn Coils in He Gas up to 17 K," Proc. 5th Symp. Eng. Probl. Fusion Res. Princeton (1973) 582-586.

42. S. L. Wipf, "Introduction to the Discussion of Stability-Review of Progress since the 1977 Stability Workshop," Proc. of the IIR Workshop on the Stability of Superconductors in He I and He II, 16-19 November 1981, CEN Saclay, France, 119-124.

43. M. Firth, L. Krempasky, F. Schmeissner, "Preliminary Work on Field-Free Particle Beam Paths from Hol low Superconducting Shielding Tubes," Proc. 3rd Int. Conf. Magnet Technology, Hamburg, 1970, 1178-1189. 
44. J. F. Bussiere, "The Development of Low-Loss $\mathrm{Nb}_{3} \mathrm{Sn}$ for AC Power Transmission: A Review," IEEE Trans. Magnetics, MAG-13, 131-137 (1977).

45. J. K. Hulm, B. T. Matthias, "High-Field, High-Current Superconductors," Science, 208, 881-881 (1980).

46. F. R. Fickett, Materials at Low Temperature, R. P. Reed and A. F. Clark, Eds, (Am. Soc. Met., Metals Park, Ohio, 1983), Chap. 5. (See also Ref. 22, Figs. 6.9 and 6.11.)

47. A. Dael, F. Kircher, J. Perot, "Use of Superconducting Self-Correcting Harmonic Coils for Pulsed Superconducting Dipole or Multipole Magnets," IEEE Trans. Magnetics, MAG-11, 459-462 (1975).

48. Francis C. Moon, "The Virial Theorem and Scaling Laws for Superconducting Magnet Systems," J. App1. Phys., 53, 9112-9121 (1982).

49. See patent disclosure October 8, 1982, "Optimal Use of Superconducting Magnets for High-Energy Charged-Particle Accelerators," S. L. Wipf. (Los Alamos National Laboratory document in preparation). 